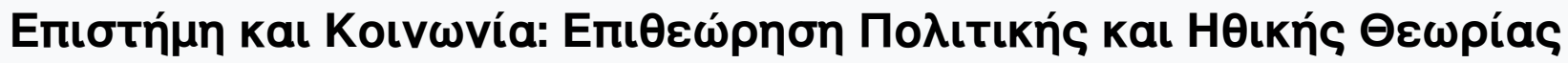

Tóp. 7 (2001)

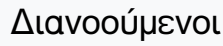

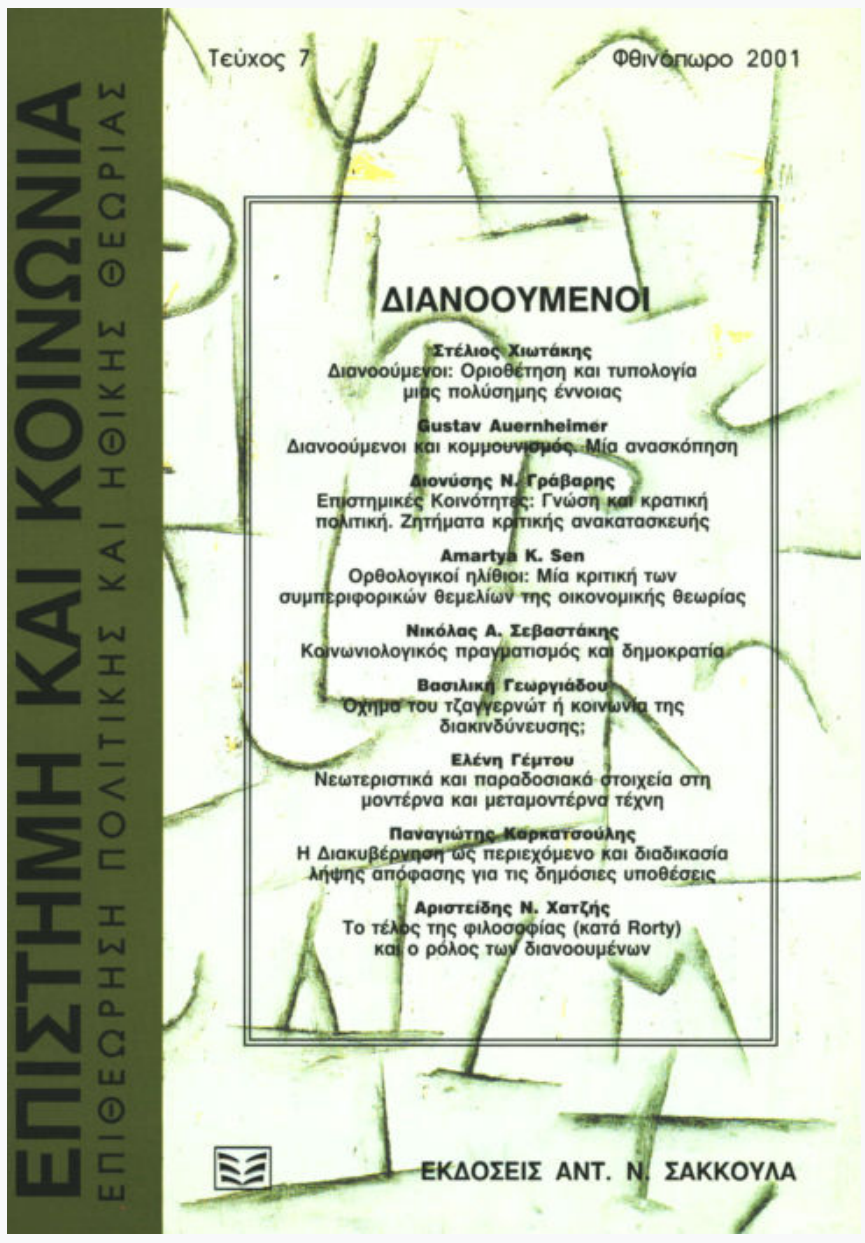

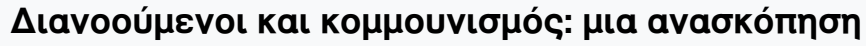

Gustav Auernheimer

doi: $\underline{10.12681 / \text { sas. } 627}$

Copyright $\odot$ 2015, Gustav Auernheimer

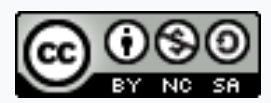

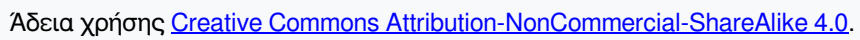

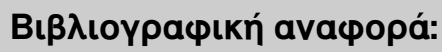

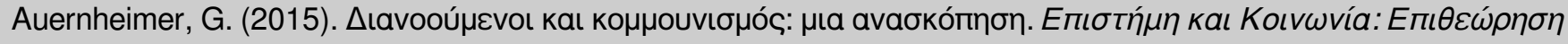

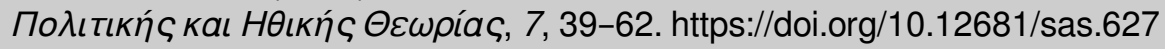




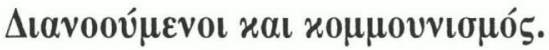

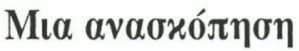

\section{Gustav Auernheimer ${ }^{*}$}

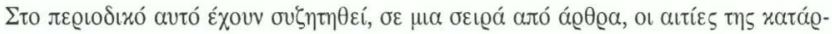

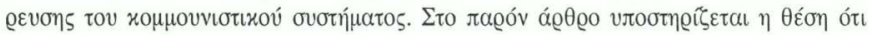

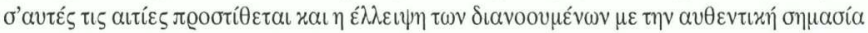

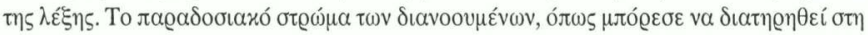

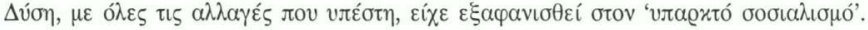

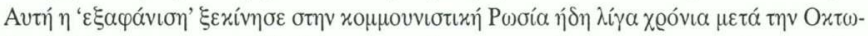

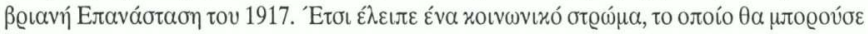

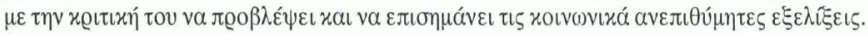

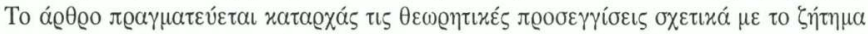

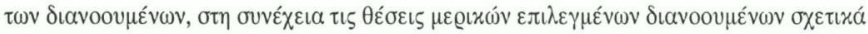

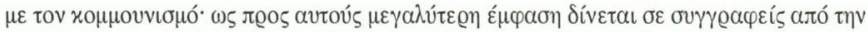

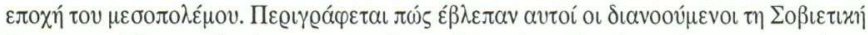

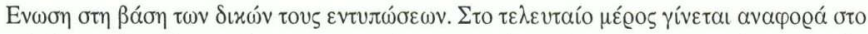

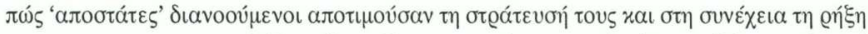

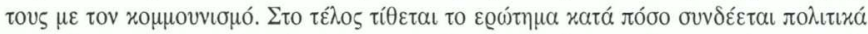

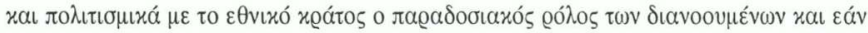

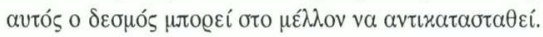

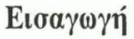

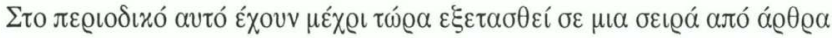

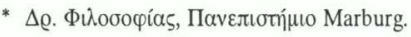




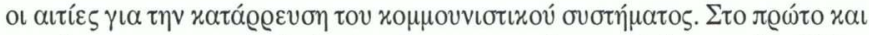

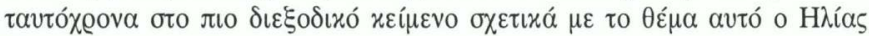

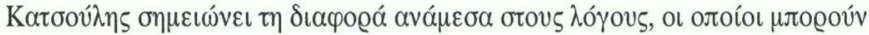

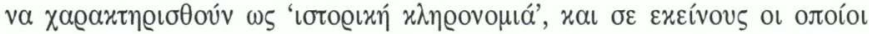

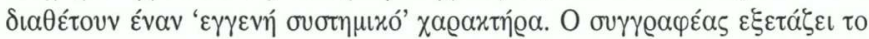

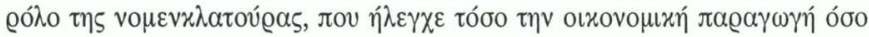

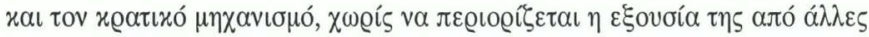

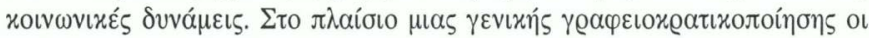

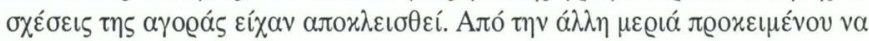

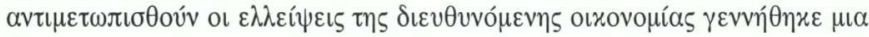

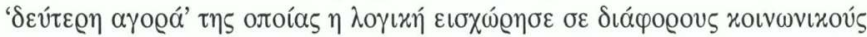

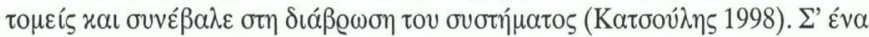

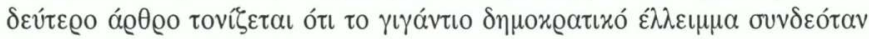

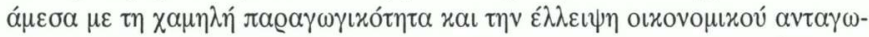

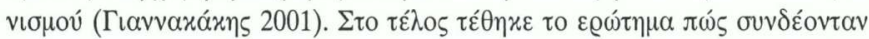

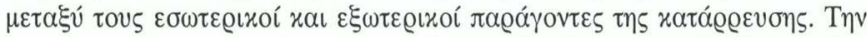

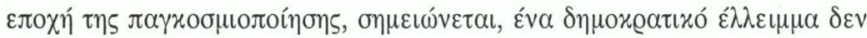

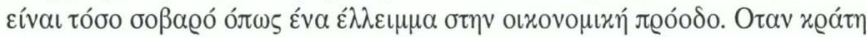

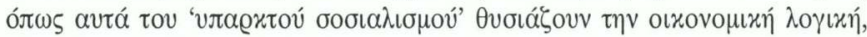

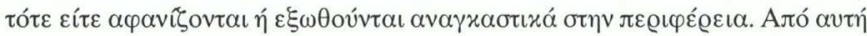

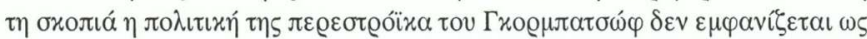

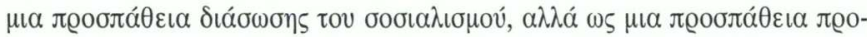

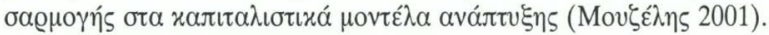

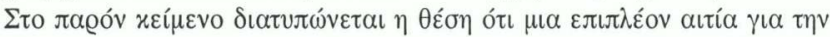

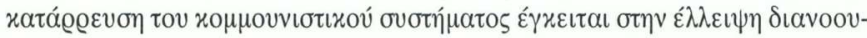

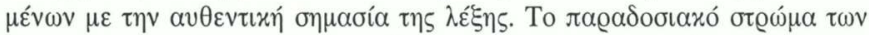

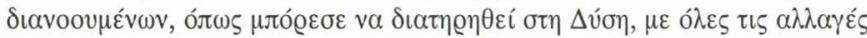

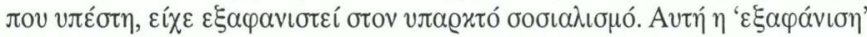

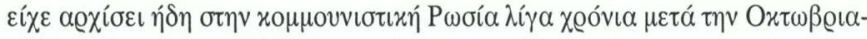

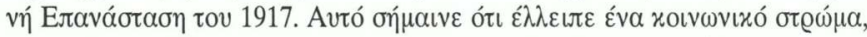

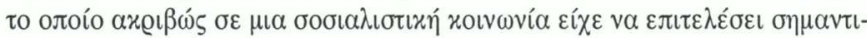

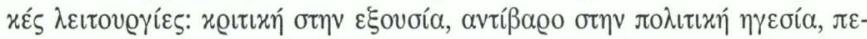

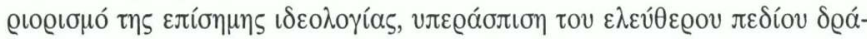

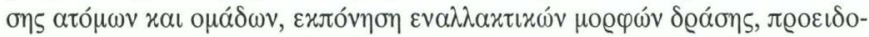

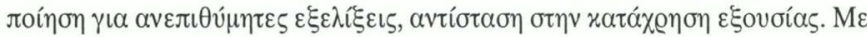

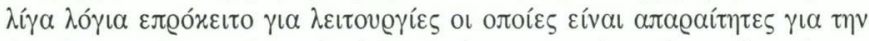

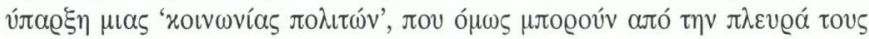




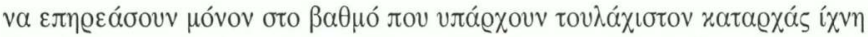

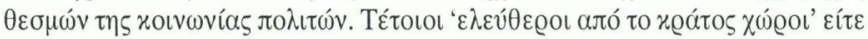

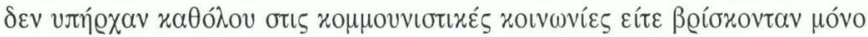

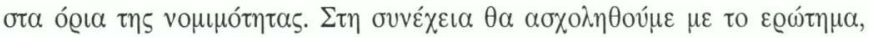

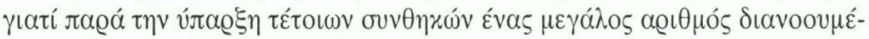

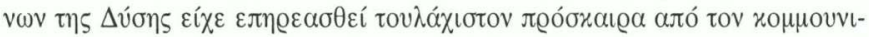

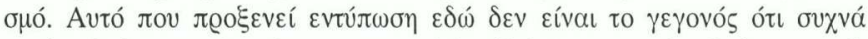

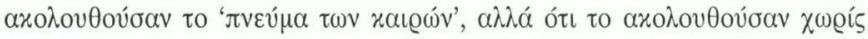

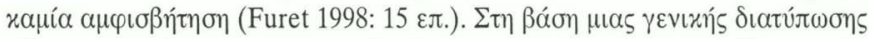

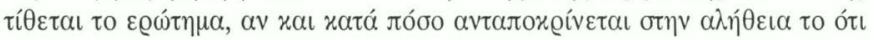

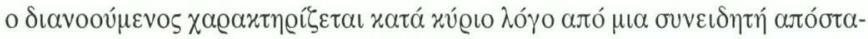

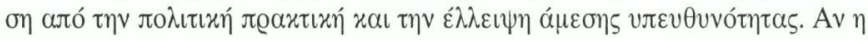

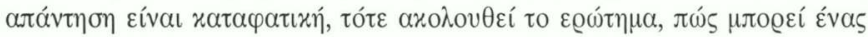

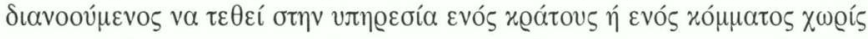

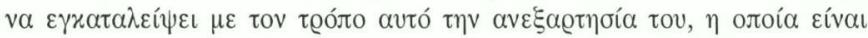

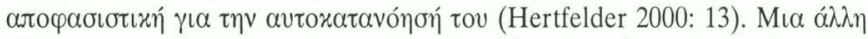

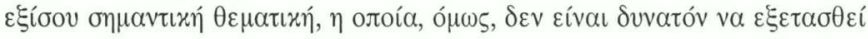

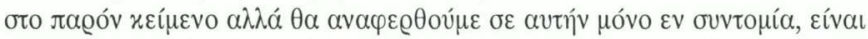

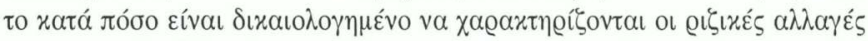

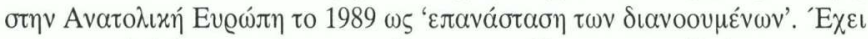

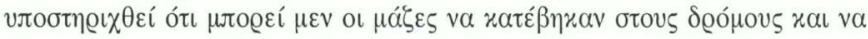

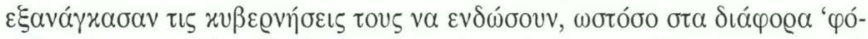

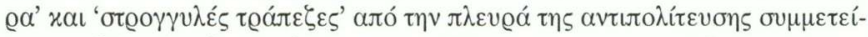

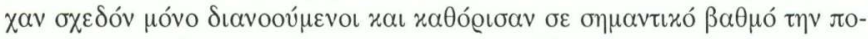

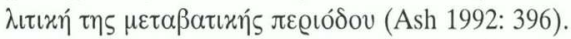

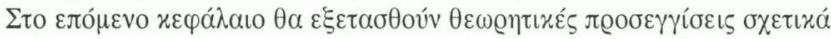

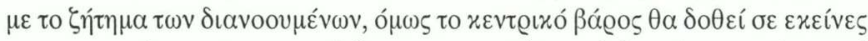

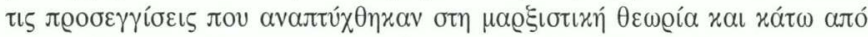

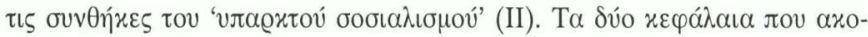

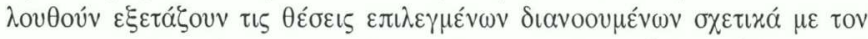

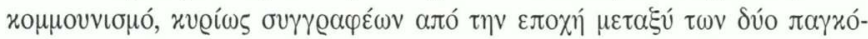

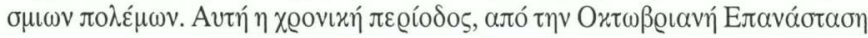

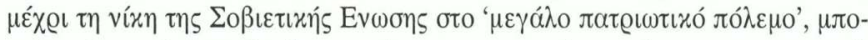

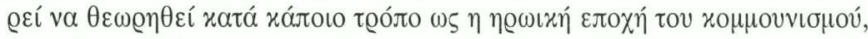

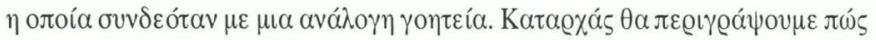

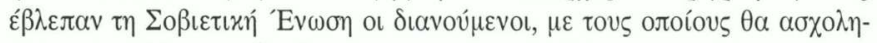

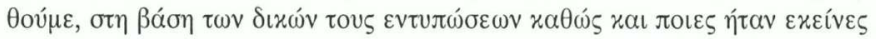




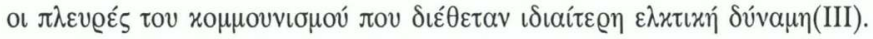

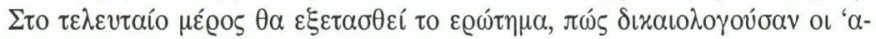

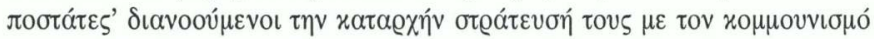

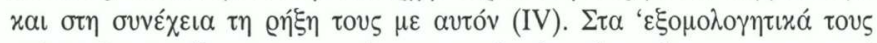

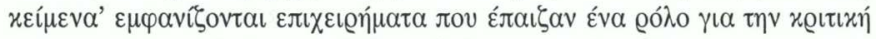

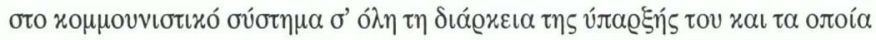

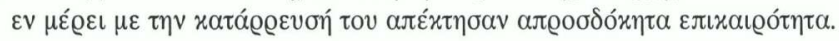

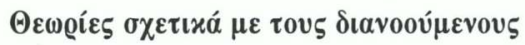

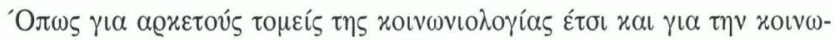

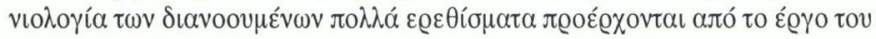

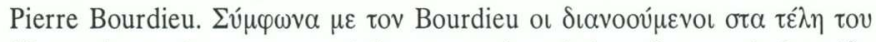

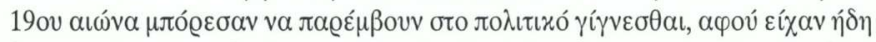

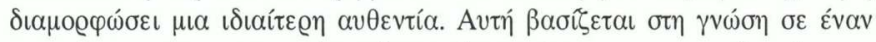

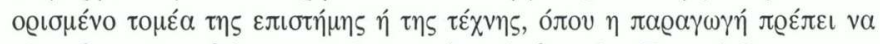

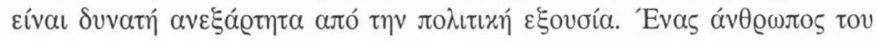

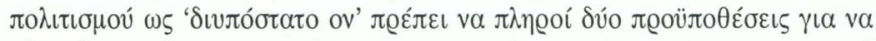

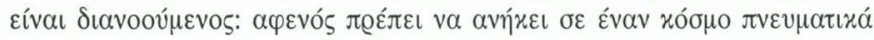

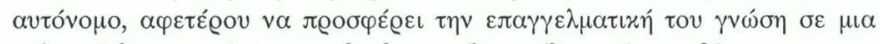

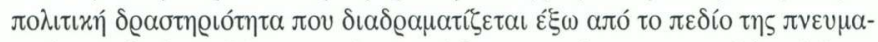

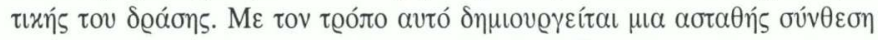

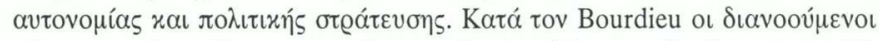

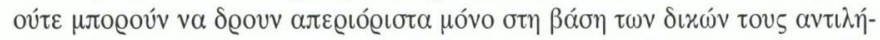

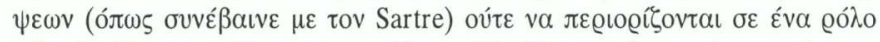

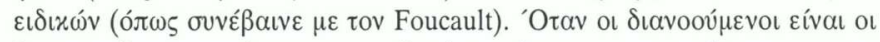

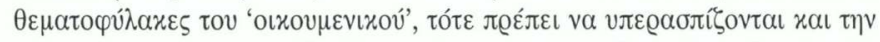

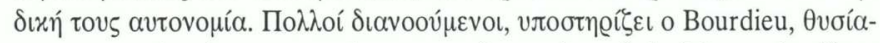

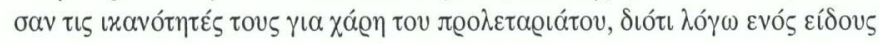

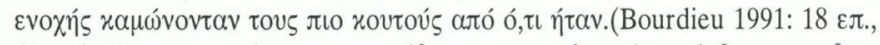

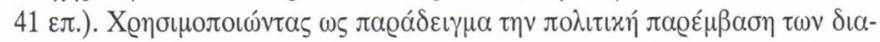

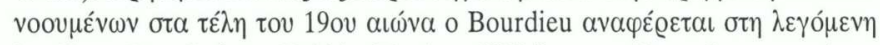

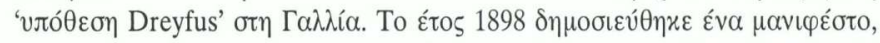

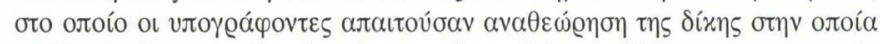

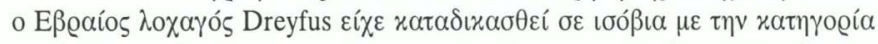

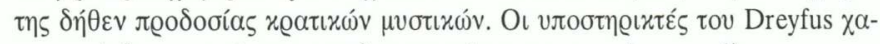

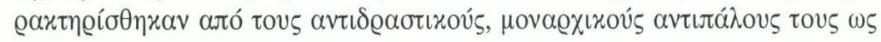




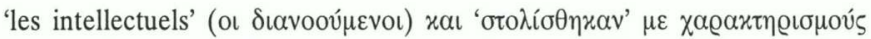

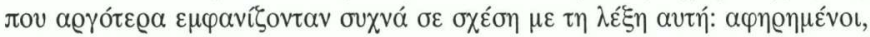

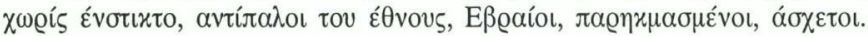

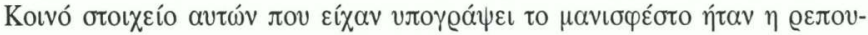

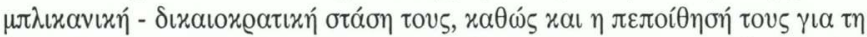

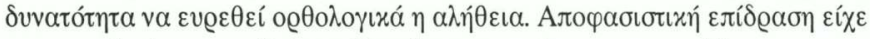

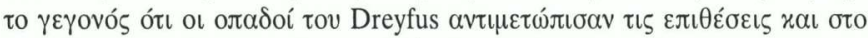

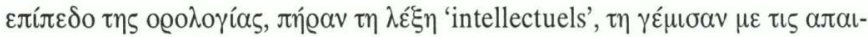

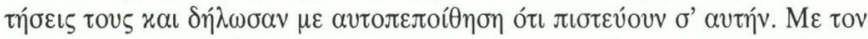

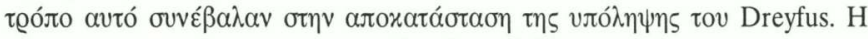

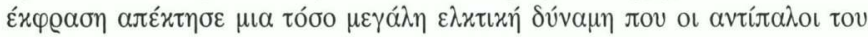

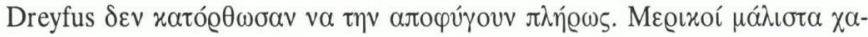

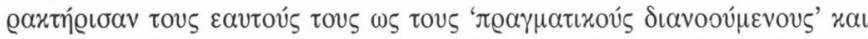

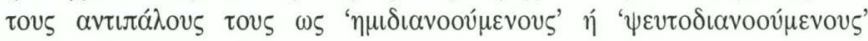
(Bering 1982: $32 \varepsilon \pi$.).

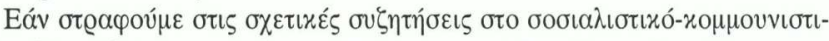

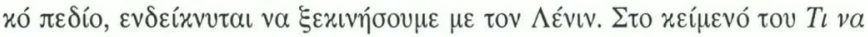

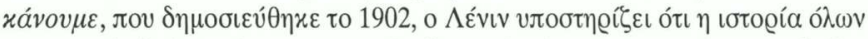

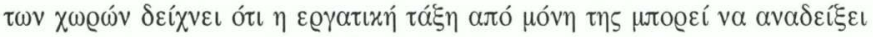

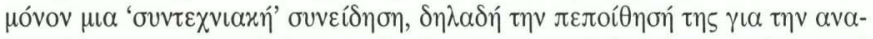

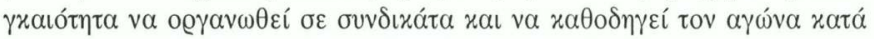

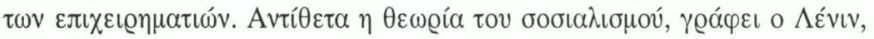

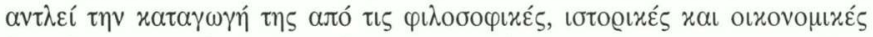

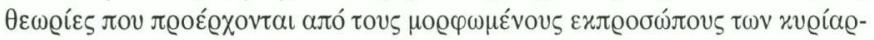

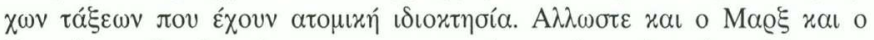

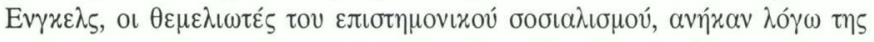

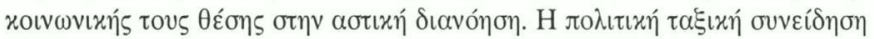

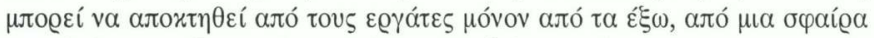

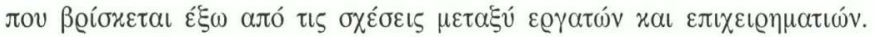

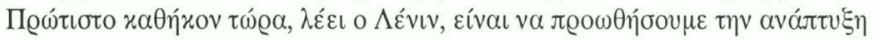

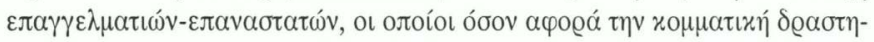

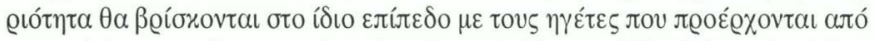

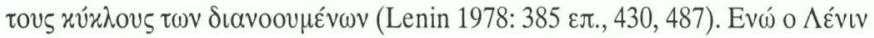

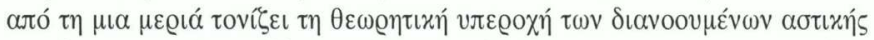

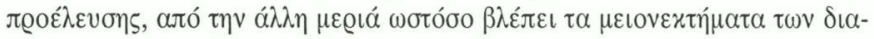

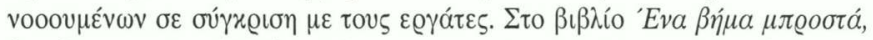

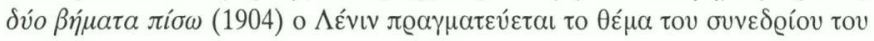




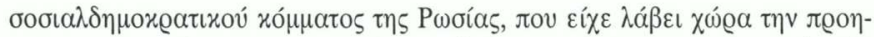

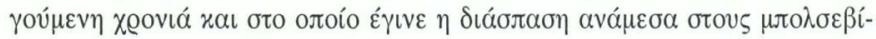

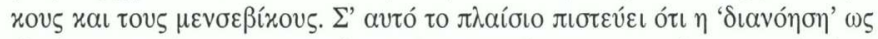

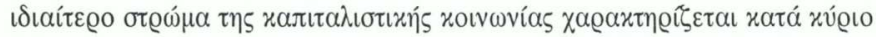

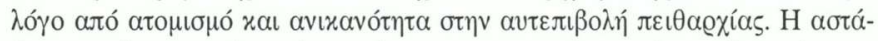

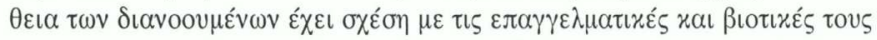

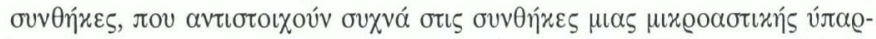

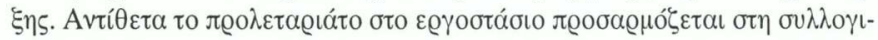

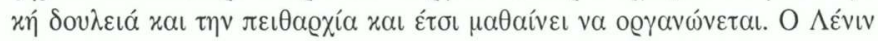

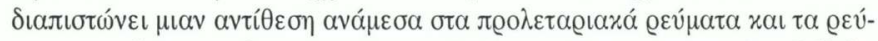

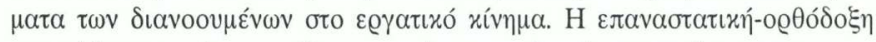

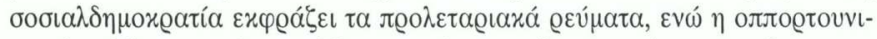

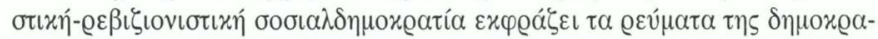

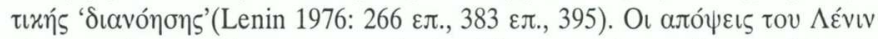

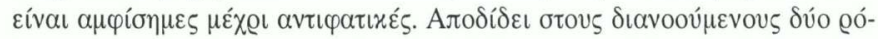

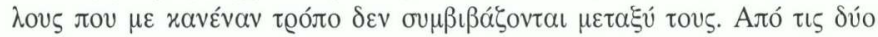

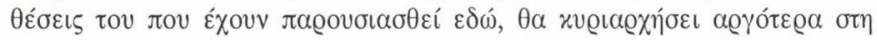
$\Sigma$

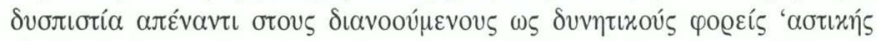

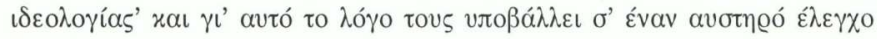

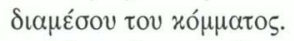

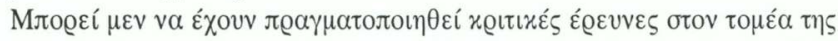

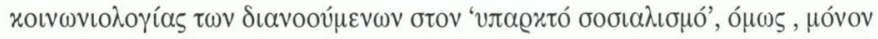

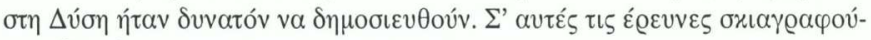

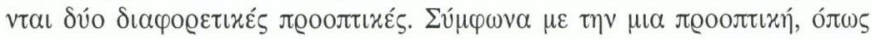

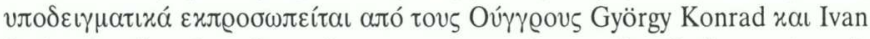

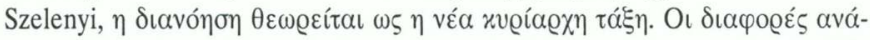

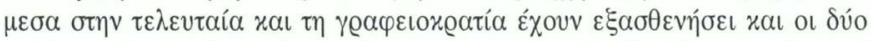

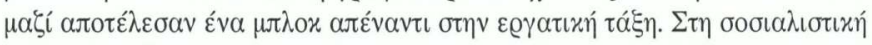

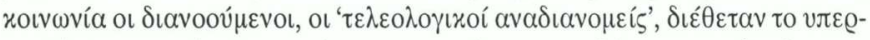

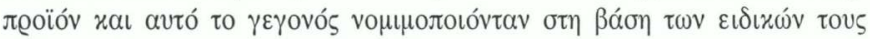

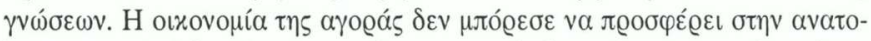

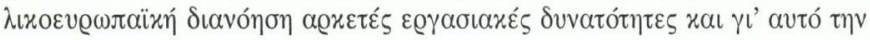

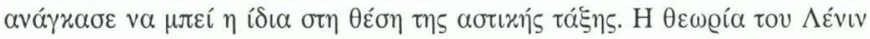

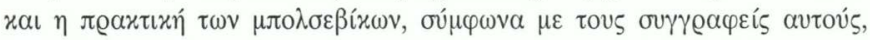

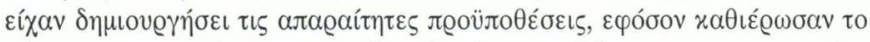

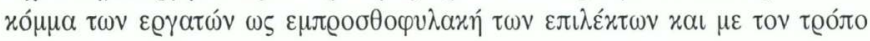




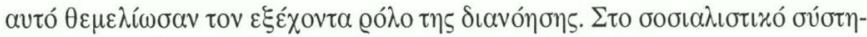

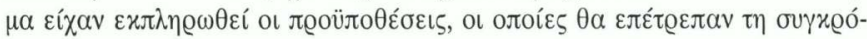

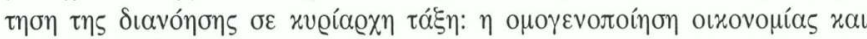

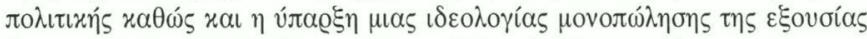

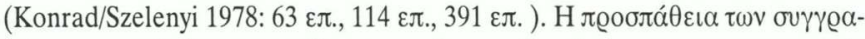

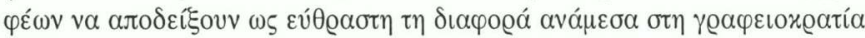

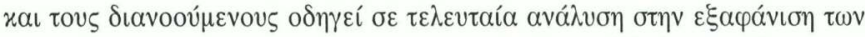

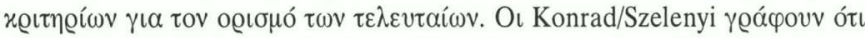

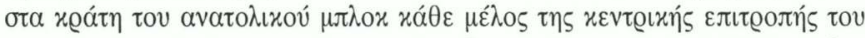

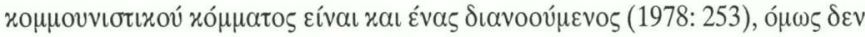

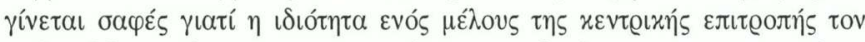

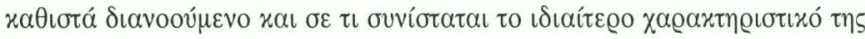

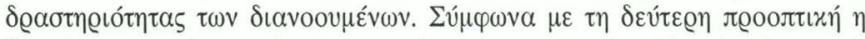

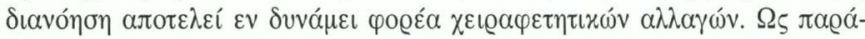

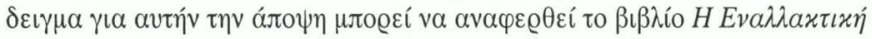

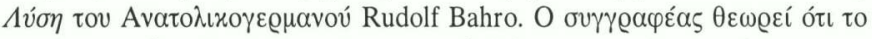

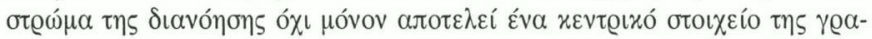

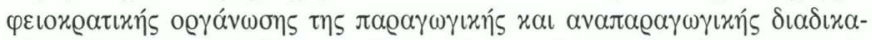

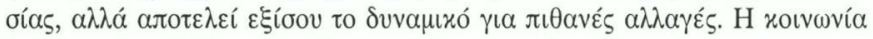

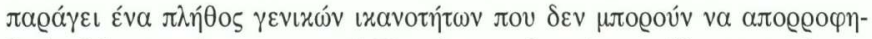

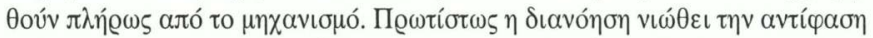

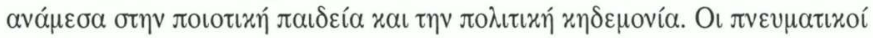

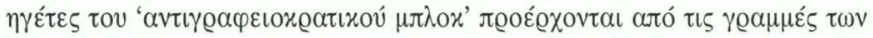

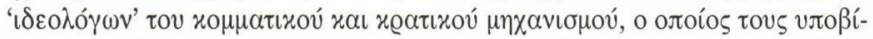

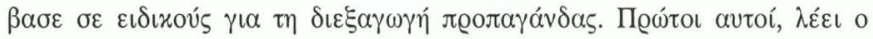

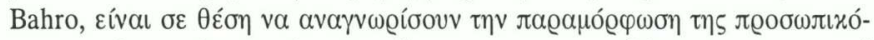

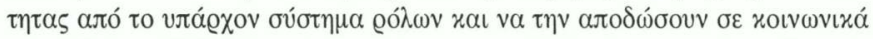

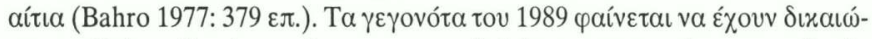

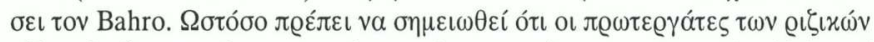

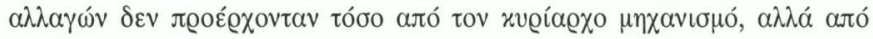

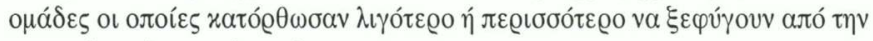

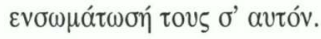

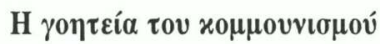

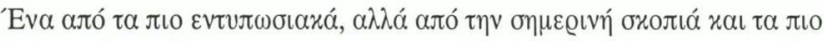

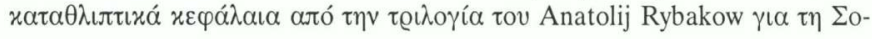




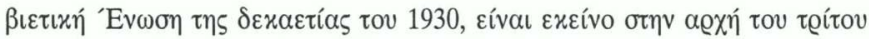

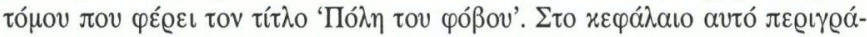

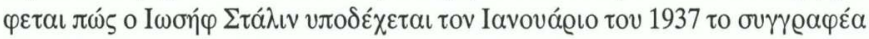

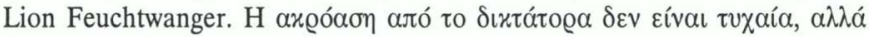

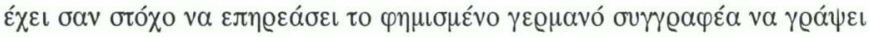

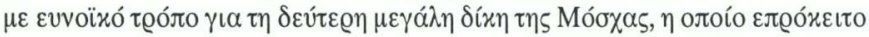

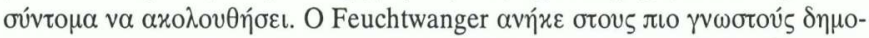

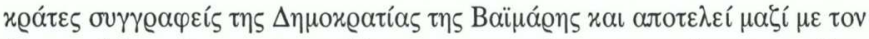

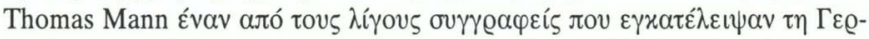

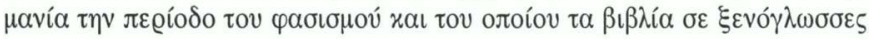

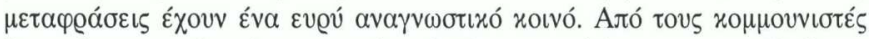

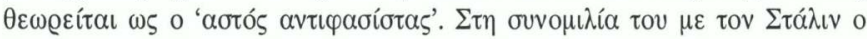

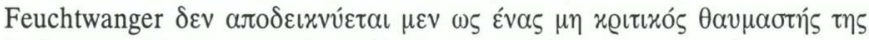

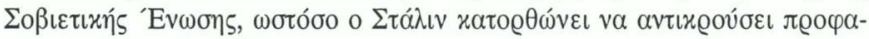

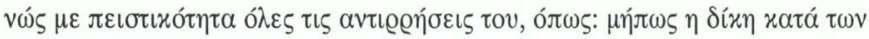

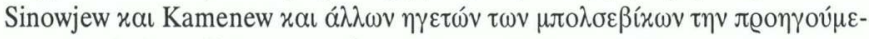

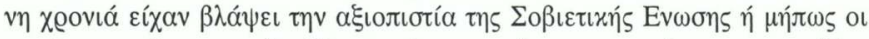

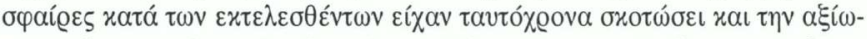

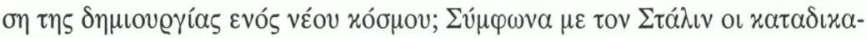

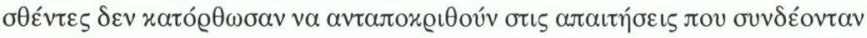

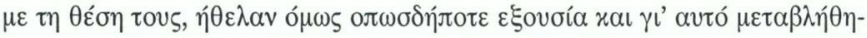

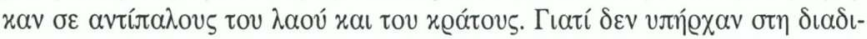

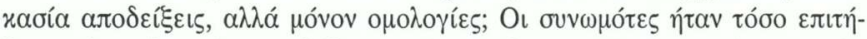

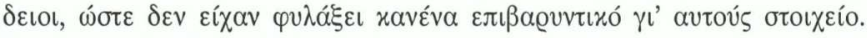

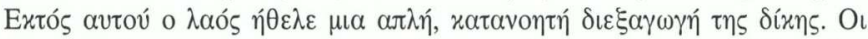

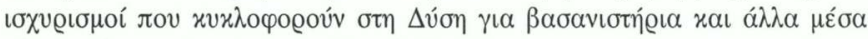

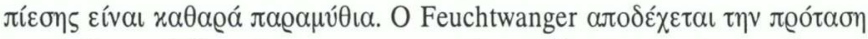

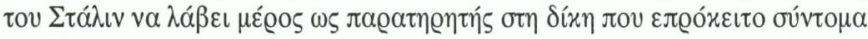

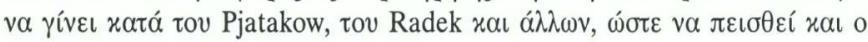

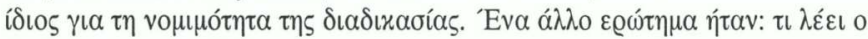

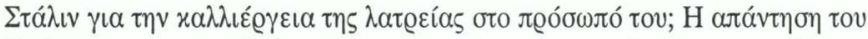

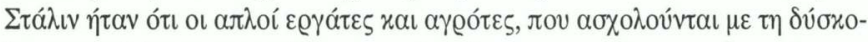

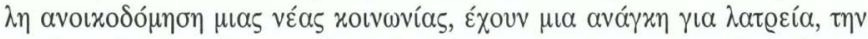

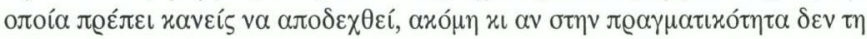

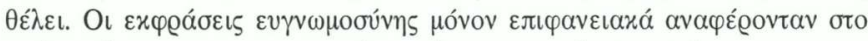

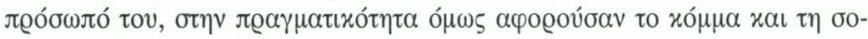

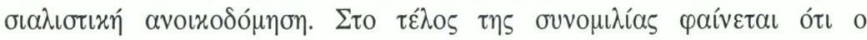




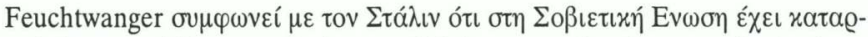

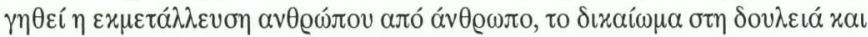

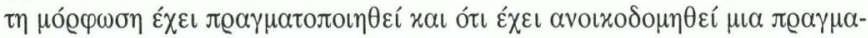

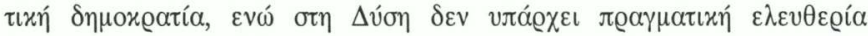
(Rybakow 1994: $21 \varepsilon \pi$.).

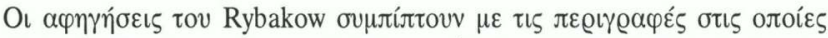

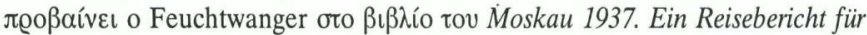

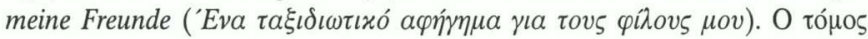

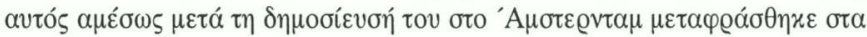

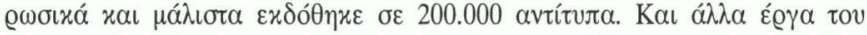

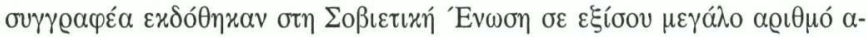

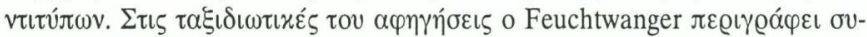

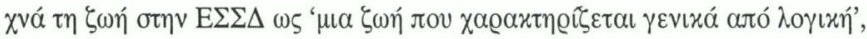

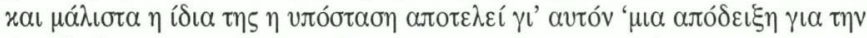

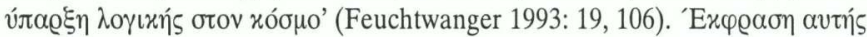

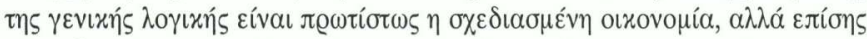

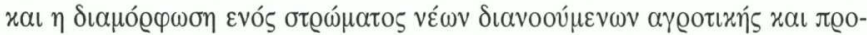

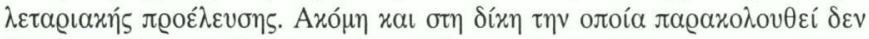

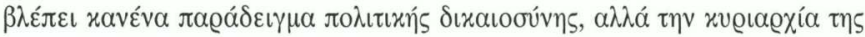

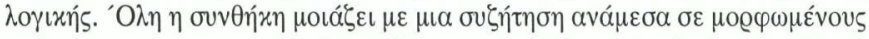
$\alpha v \theta \varrho \omega ́ \pi$ ง

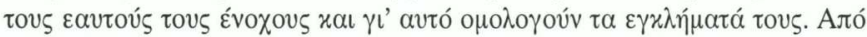

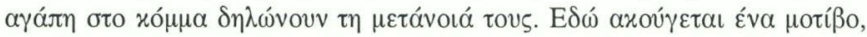

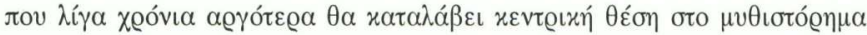

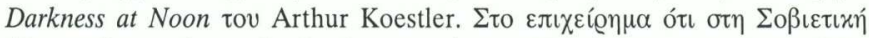

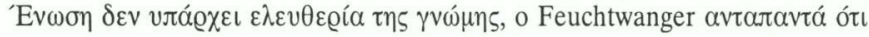

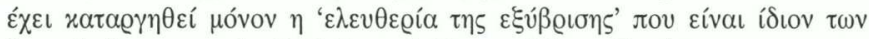

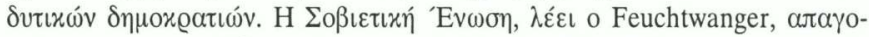

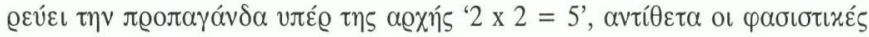

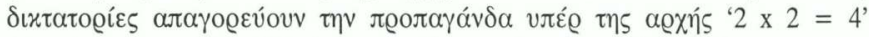

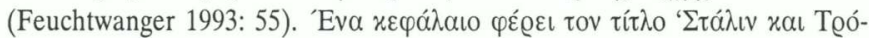

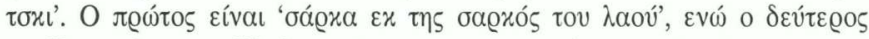

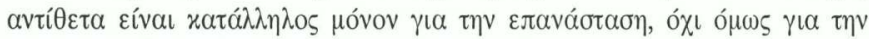

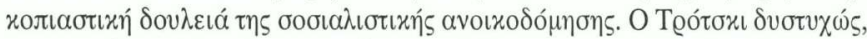

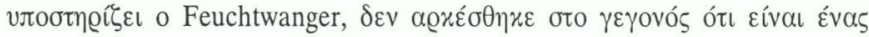

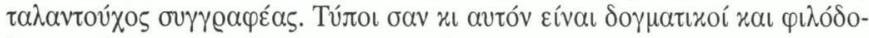

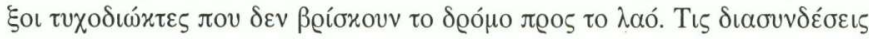




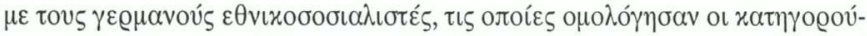

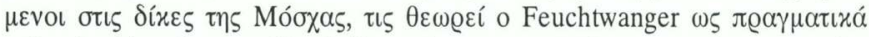

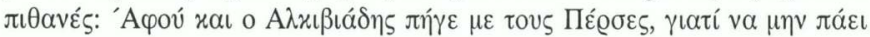

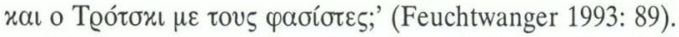

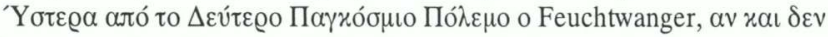

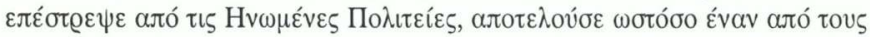

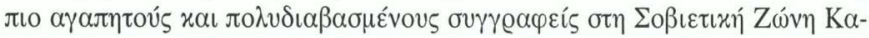

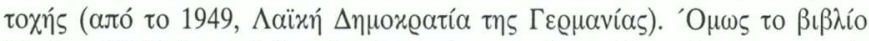

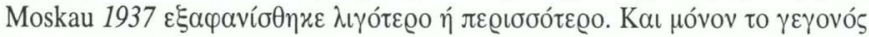

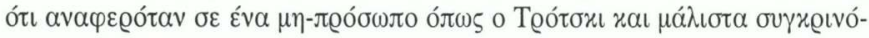

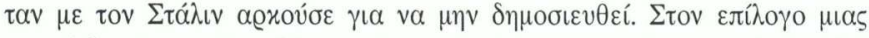

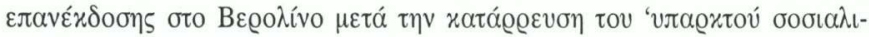

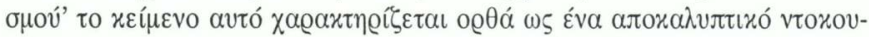

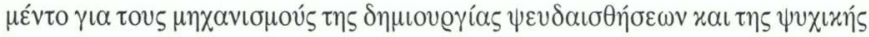

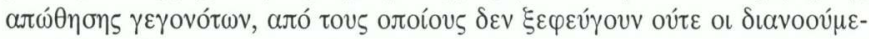

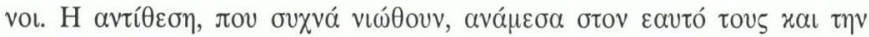

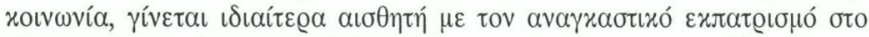

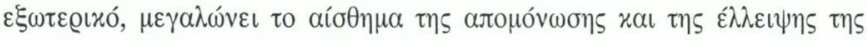

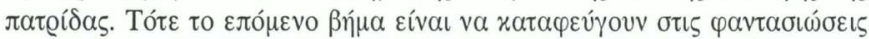

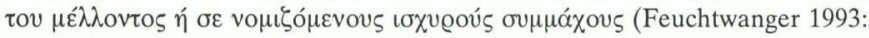
$113 \varepsilon \pi$.). O Lion Feuchtwanger $\delta \varepsilon \nu$ a

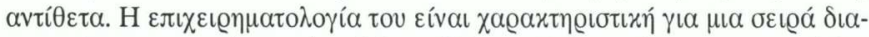

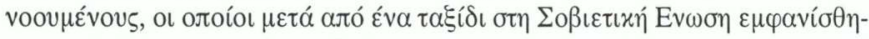

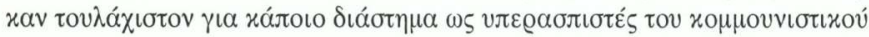

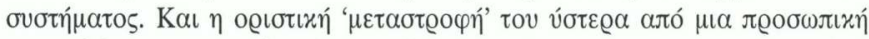

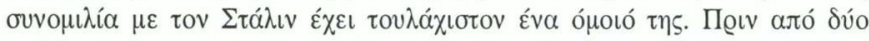

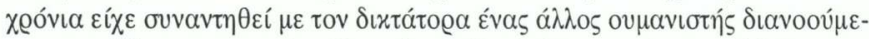

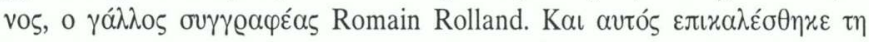

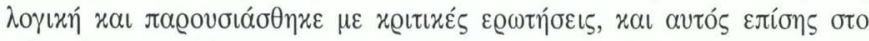

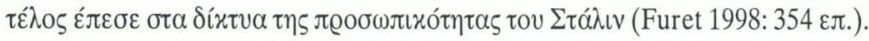

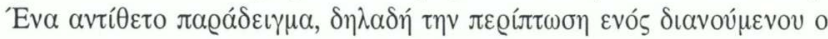

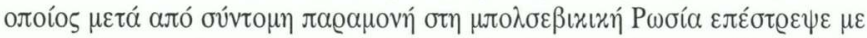

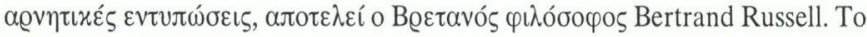

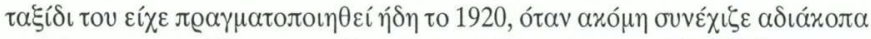

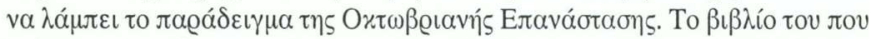

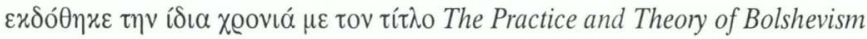

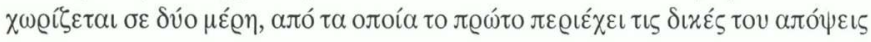




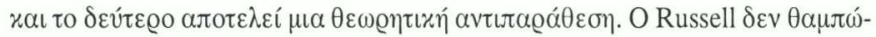

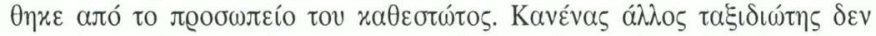

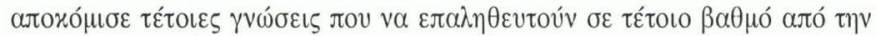

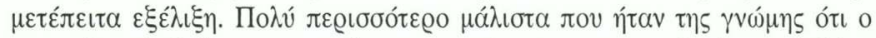

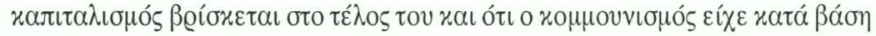

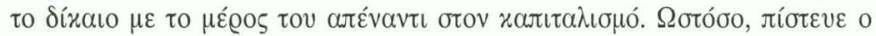

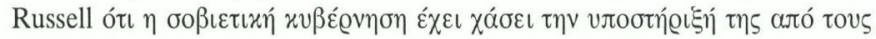

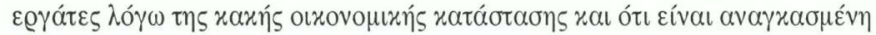

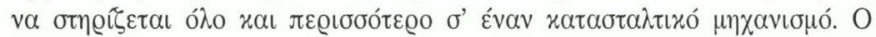

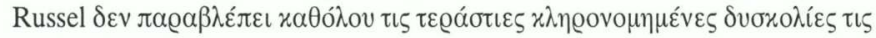

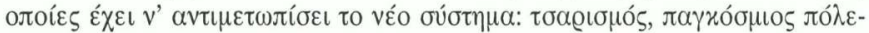

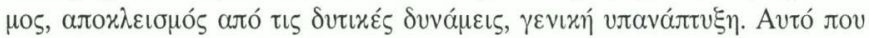

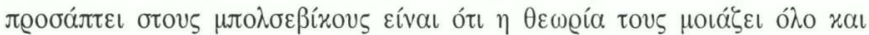

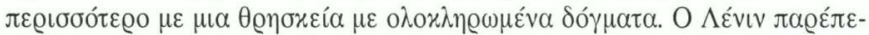

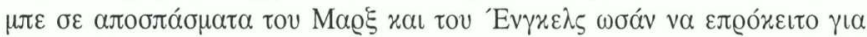

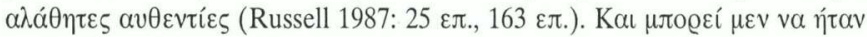

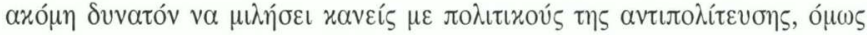

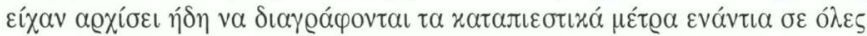

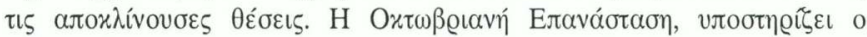

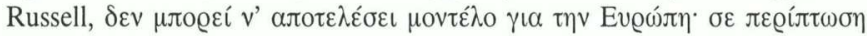

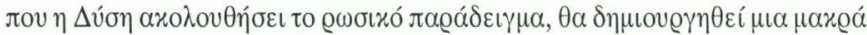

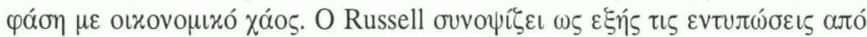

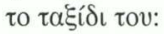

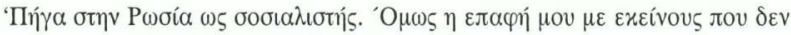

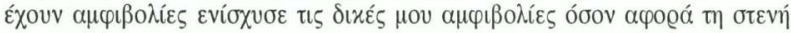

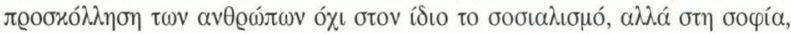
бтฤ

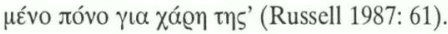

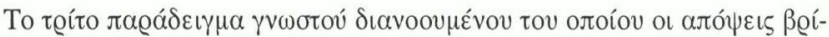

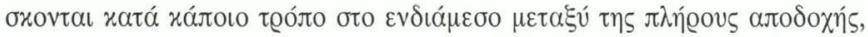

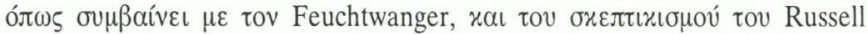

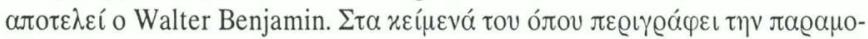

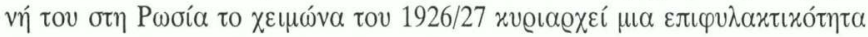

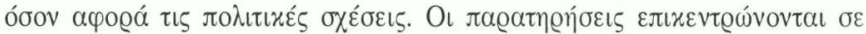

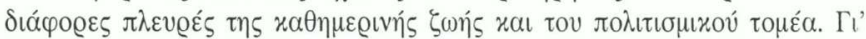

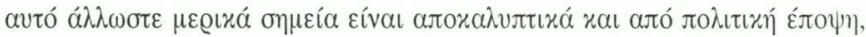

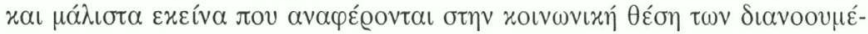




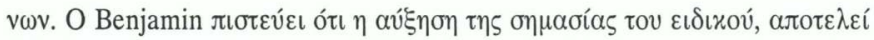

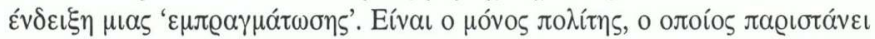

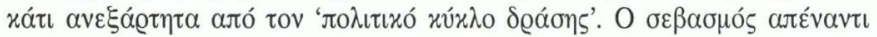

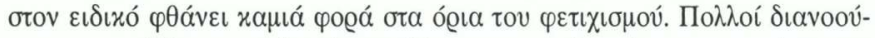

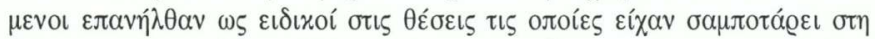

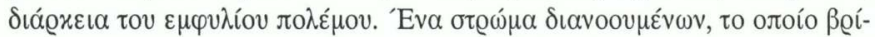

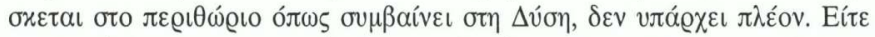

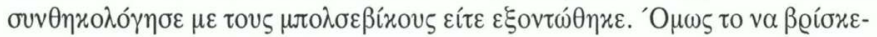

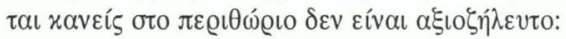

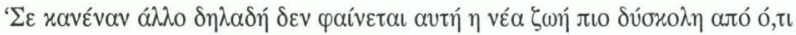

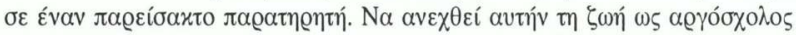

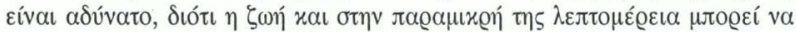

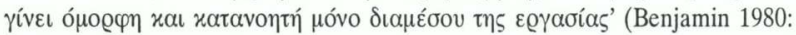
327).

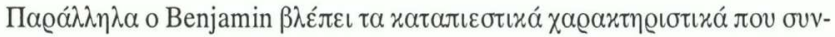

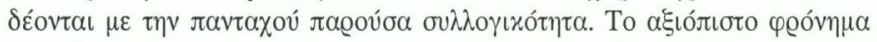

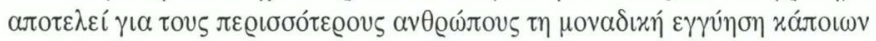

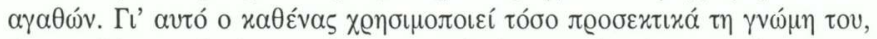

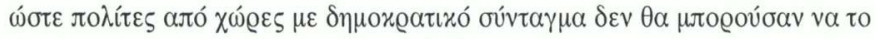

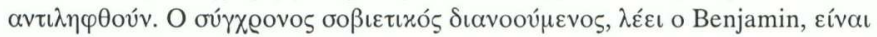

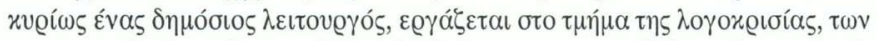

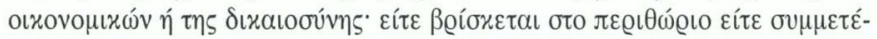

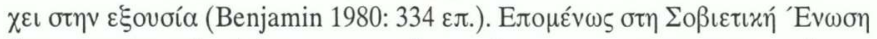

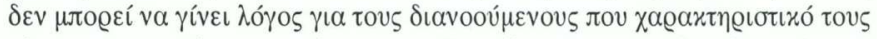

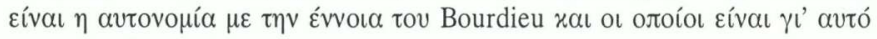

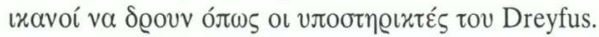

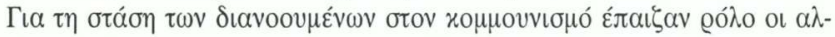

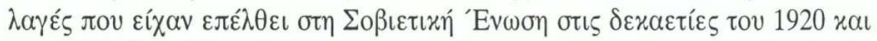

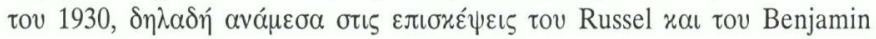

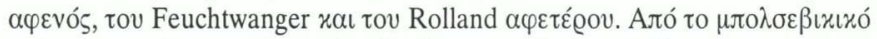

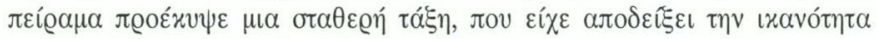

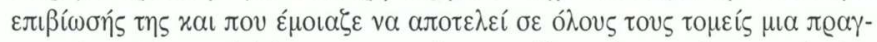

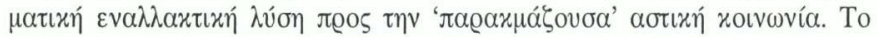

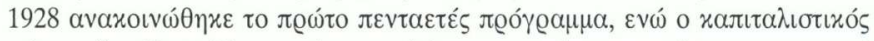

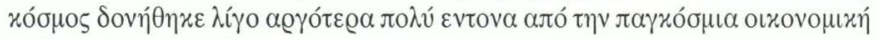

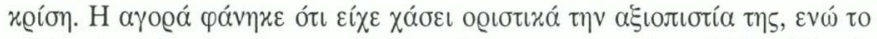

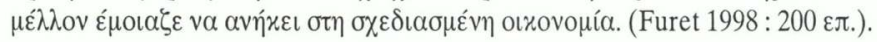




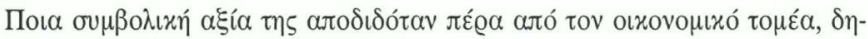

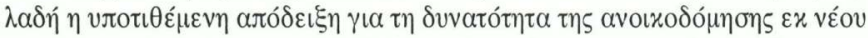

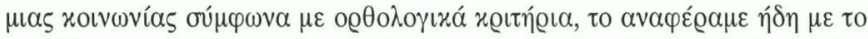

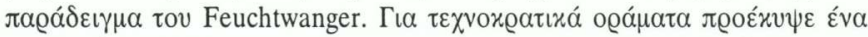

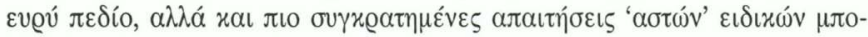

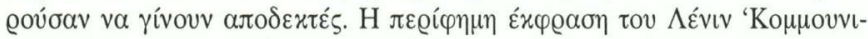

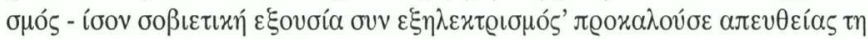

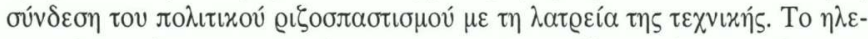

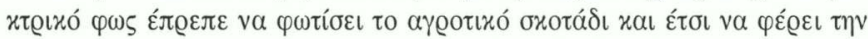

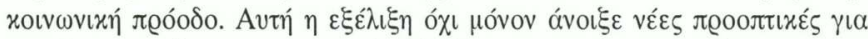

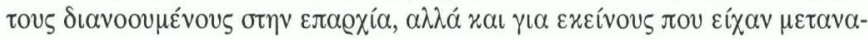

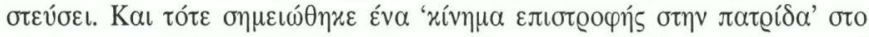

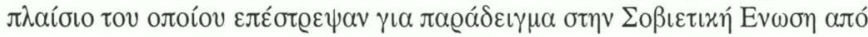

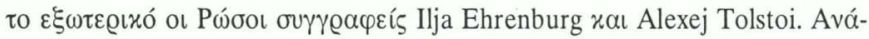

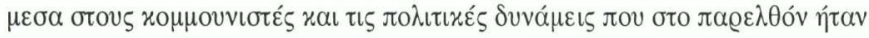

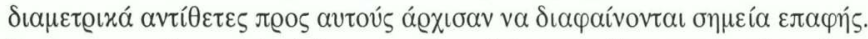

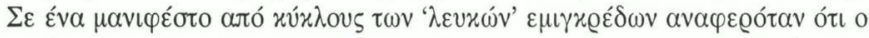

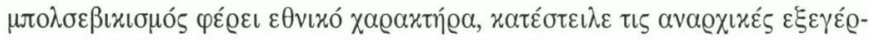

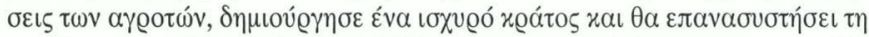

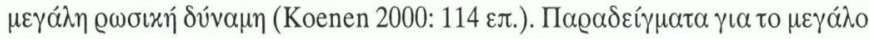

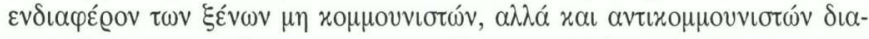

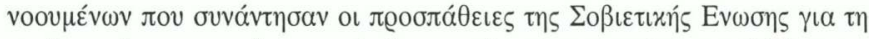

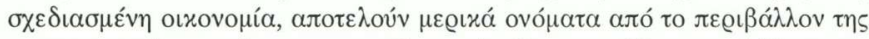

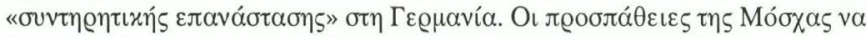

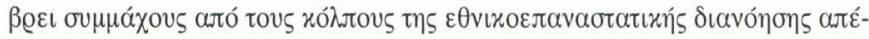

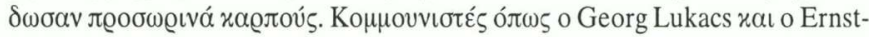

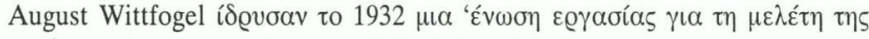

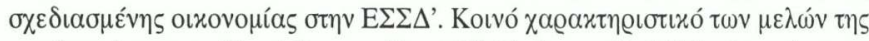

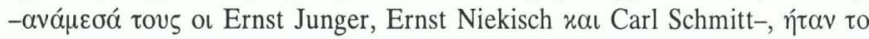

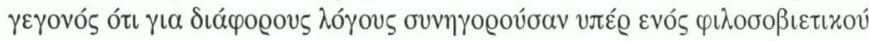

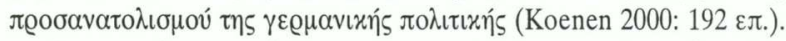

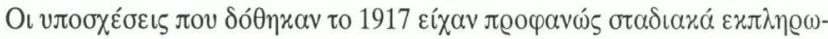
$\theta \varepsilon i ́$.

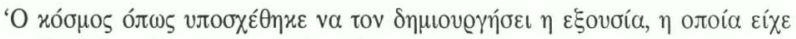

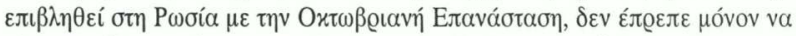

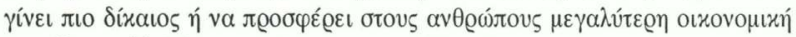

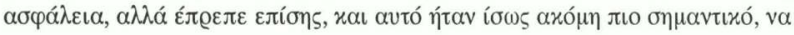




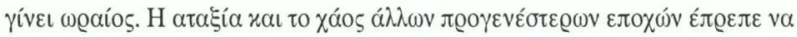

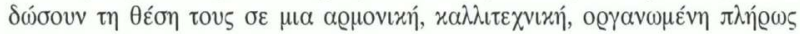

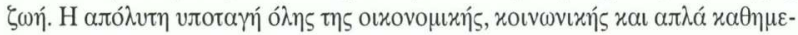

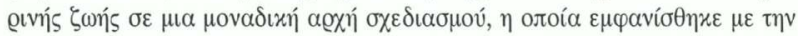

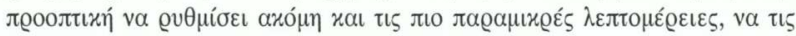

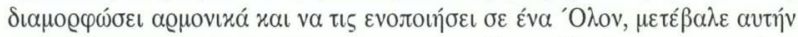

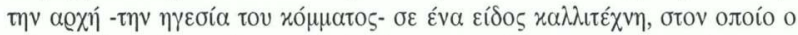

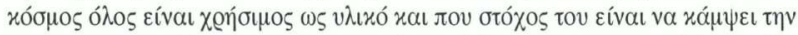

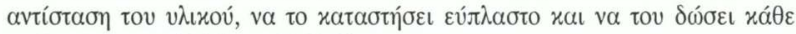

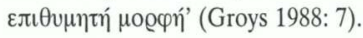

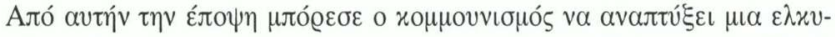

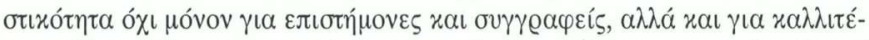

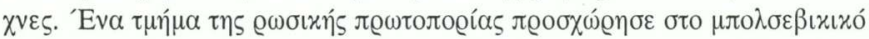

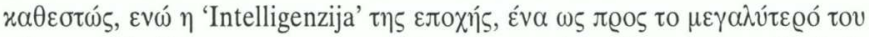

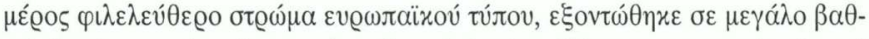

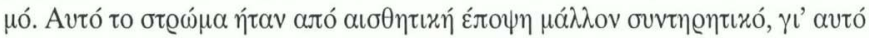

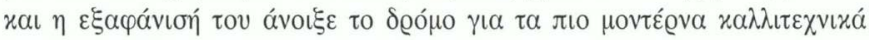

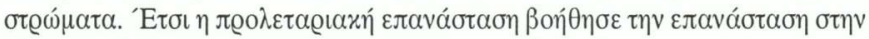

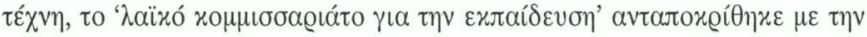

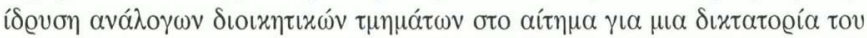

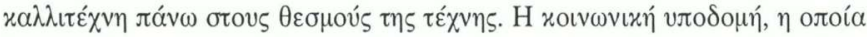

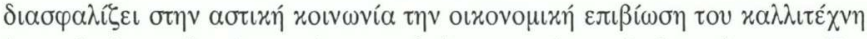

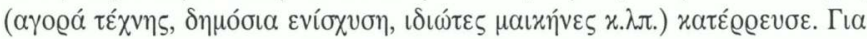

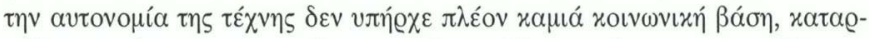

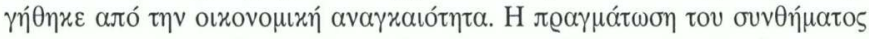

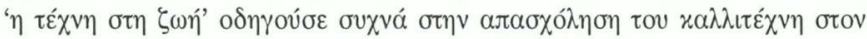

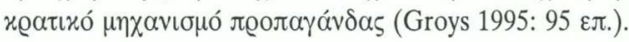

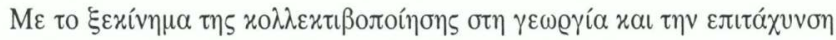

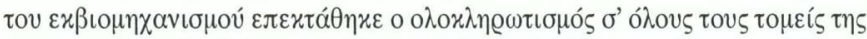

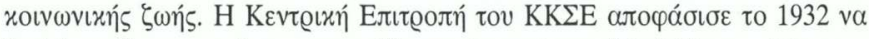

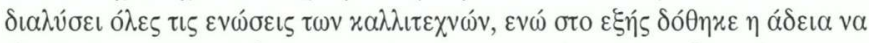

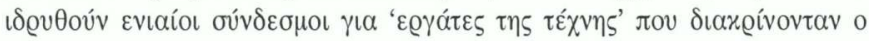

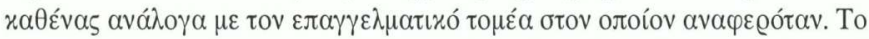

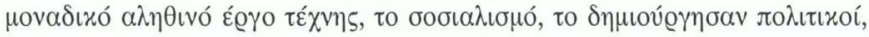

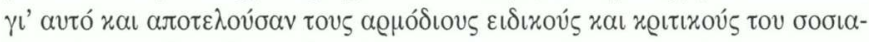

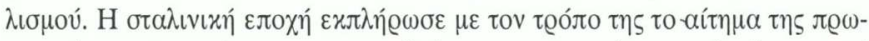

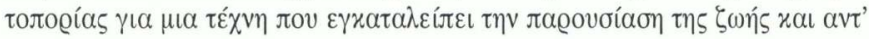




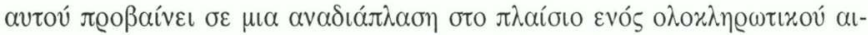

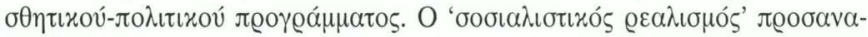

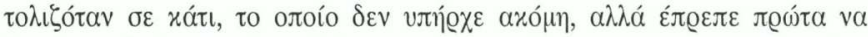

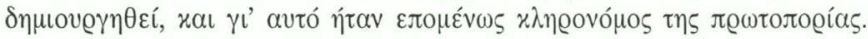

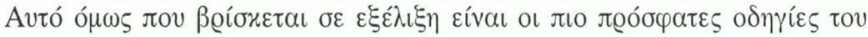

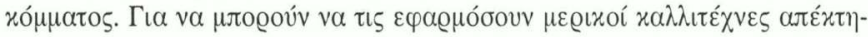

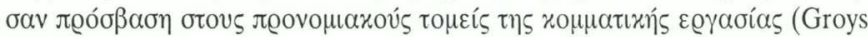

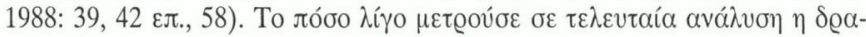

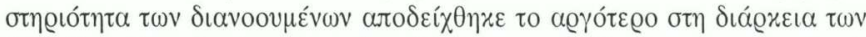

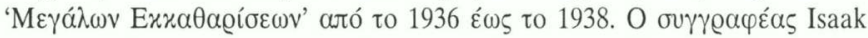

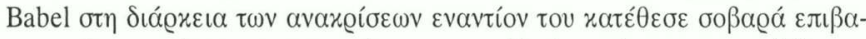

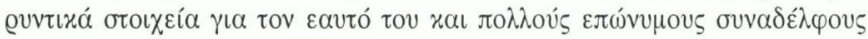

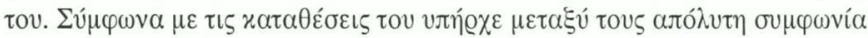

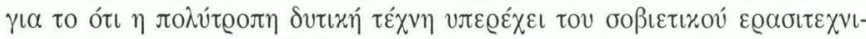

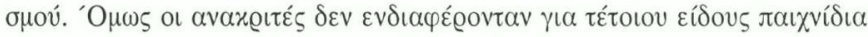

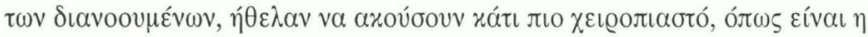

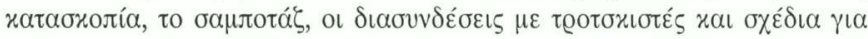

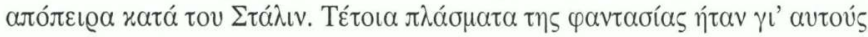

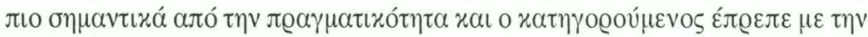

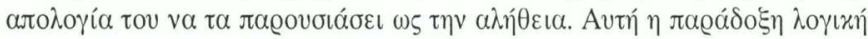

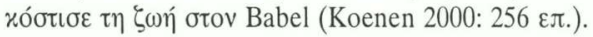

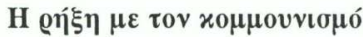

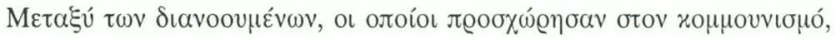

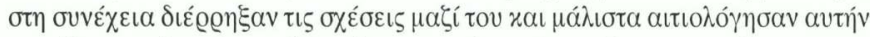

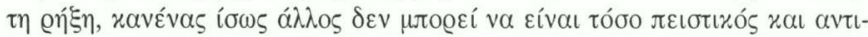

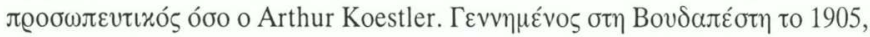

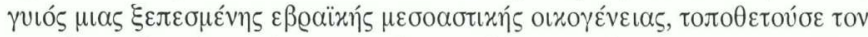

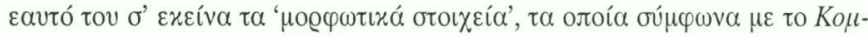

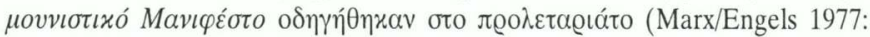

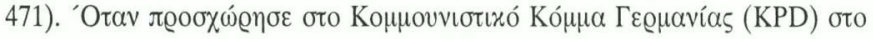

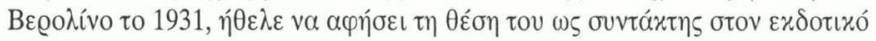

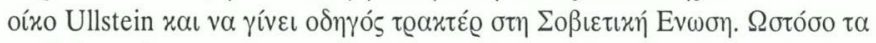

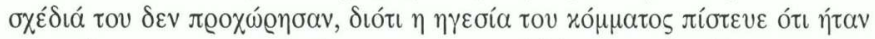

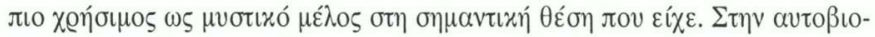

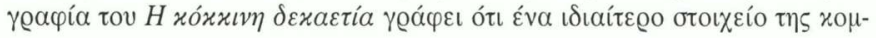




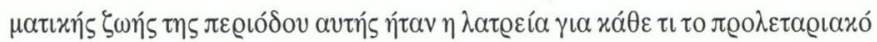

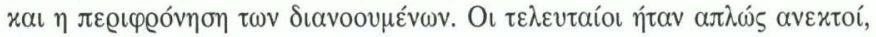

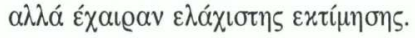

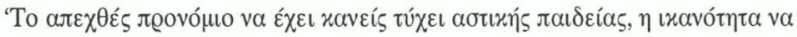

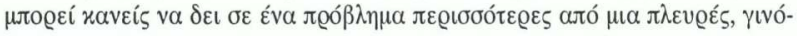

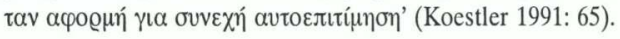

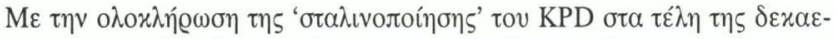

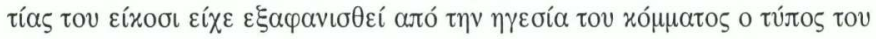

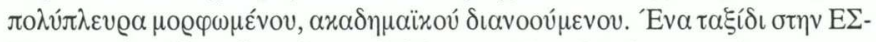

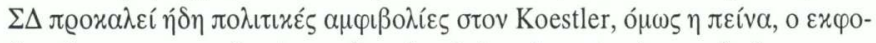

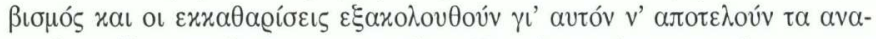

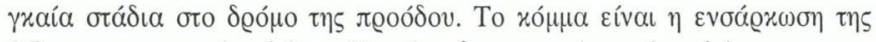

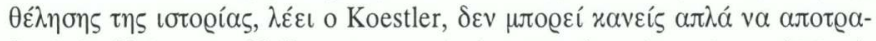

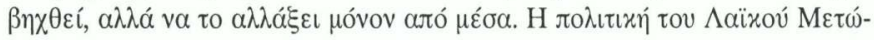

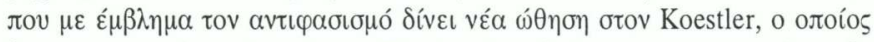

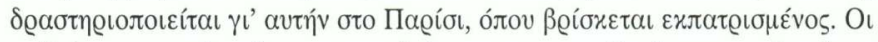

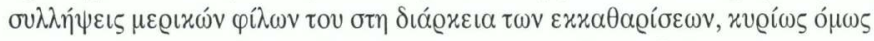

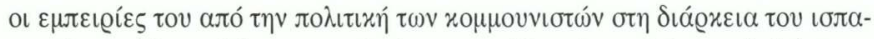

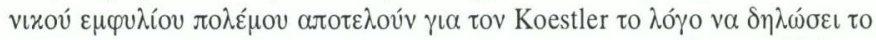

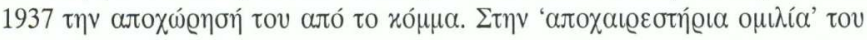

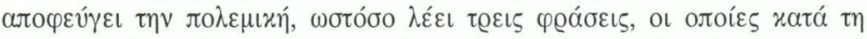

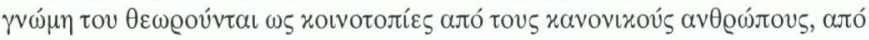

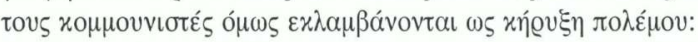

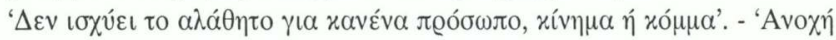

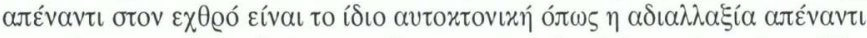

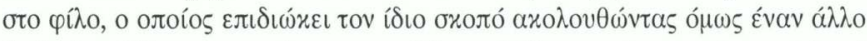

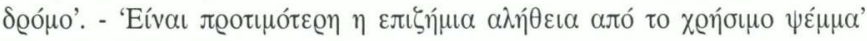
(Koestler 1991: 107).

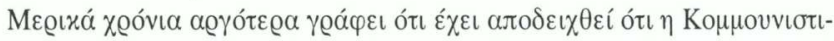

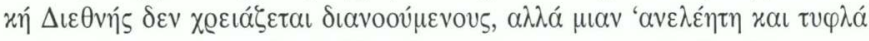

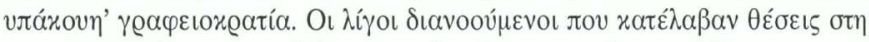

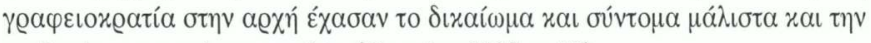

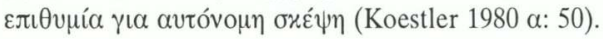

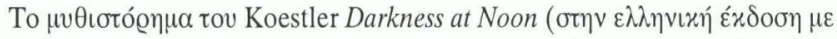

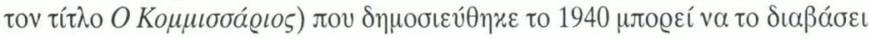

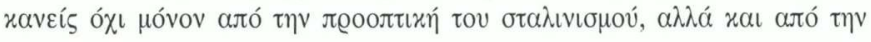




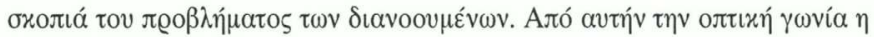

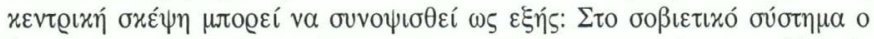

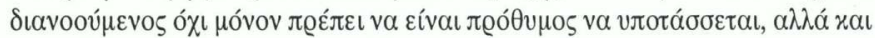

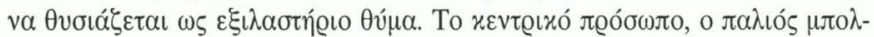

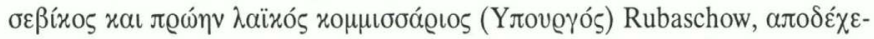

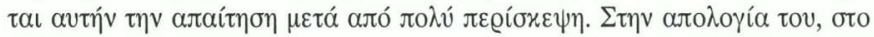

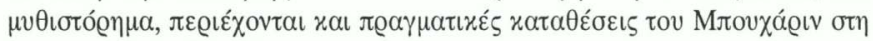

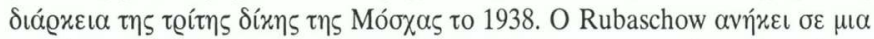

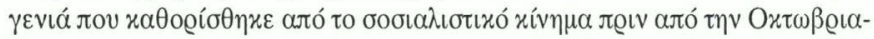

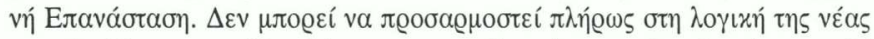

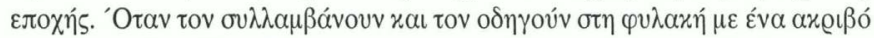

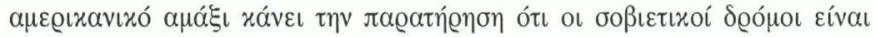

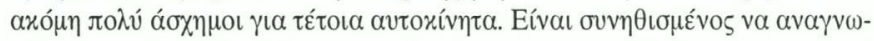

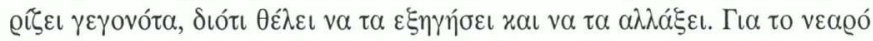

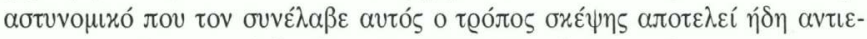

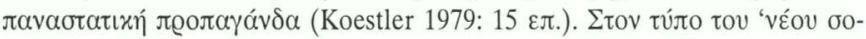

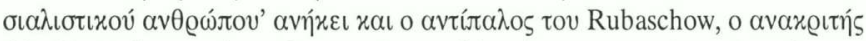

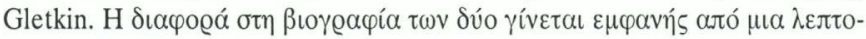

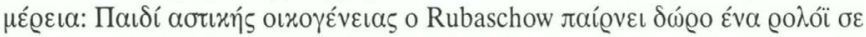

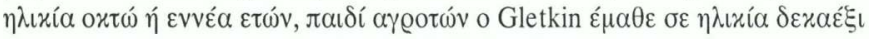

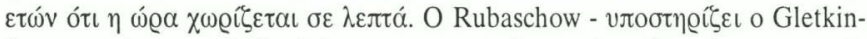

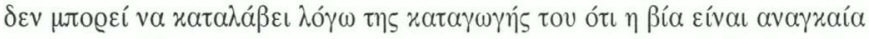

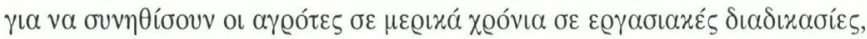

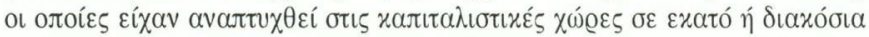

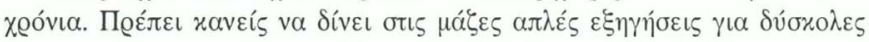

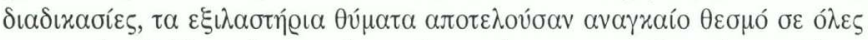

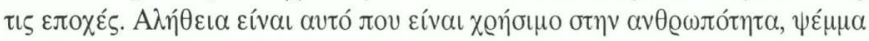

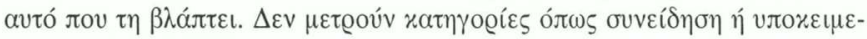

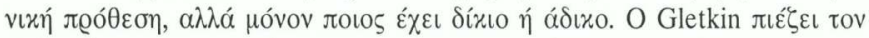

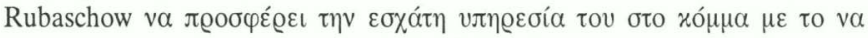

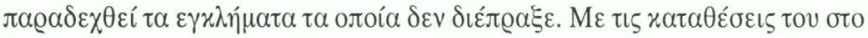

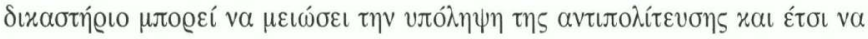

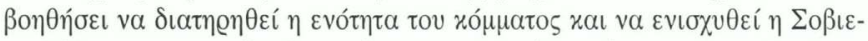

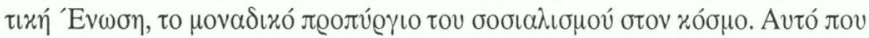

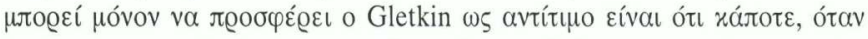

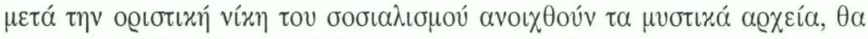

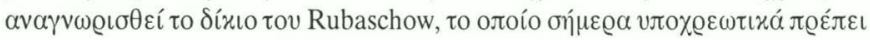




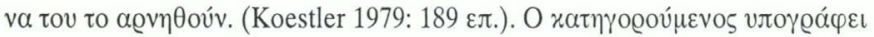

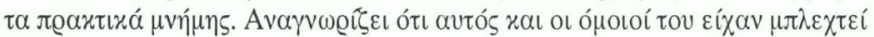

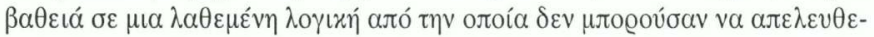

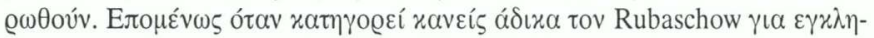

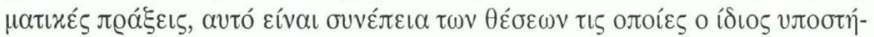

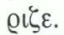

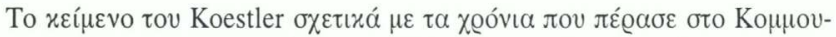

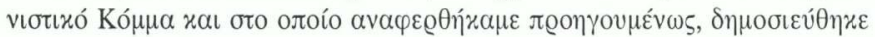

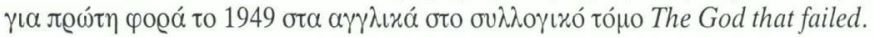

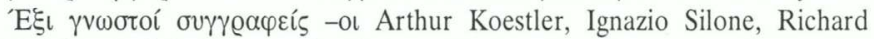

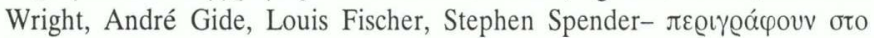

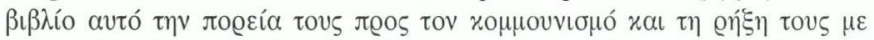

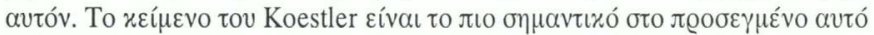

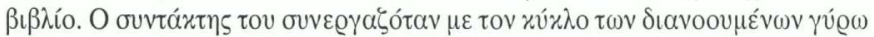

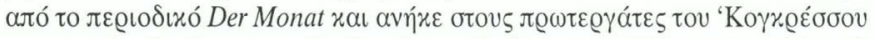

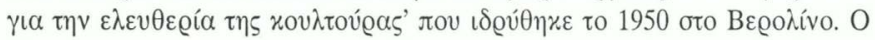

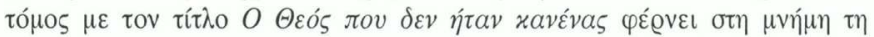

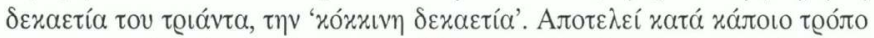

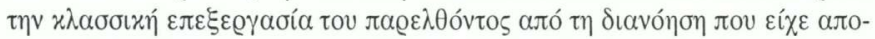

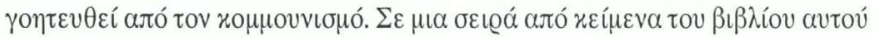

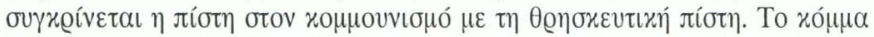

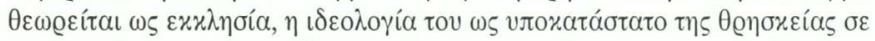

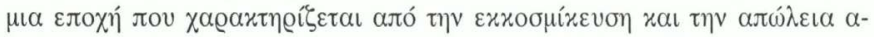

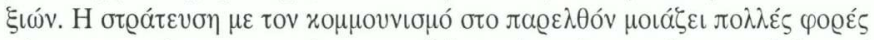

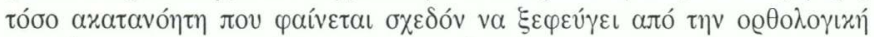

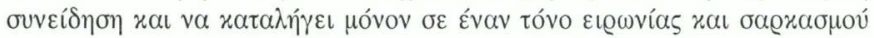

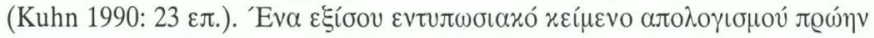

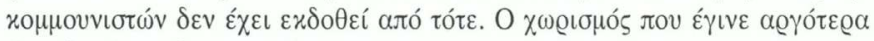

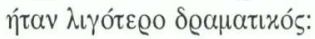

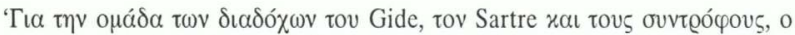

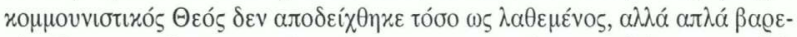

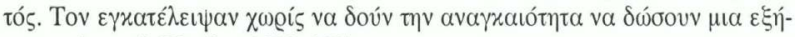

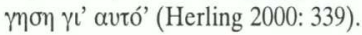

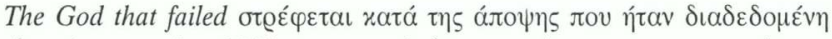

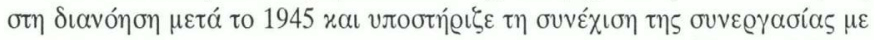

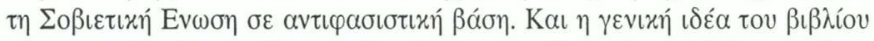

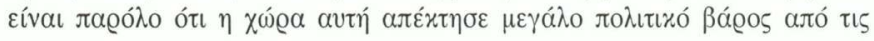




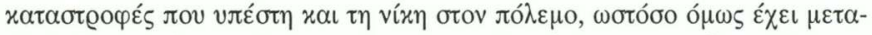

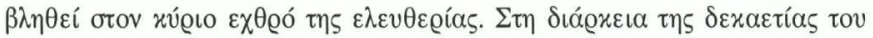

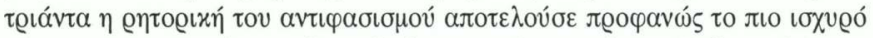

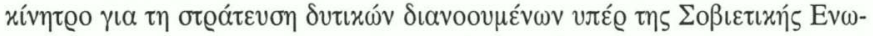

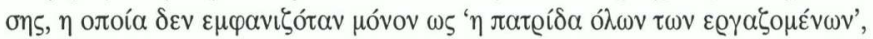

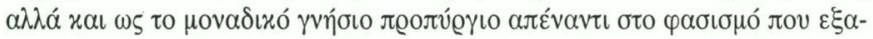

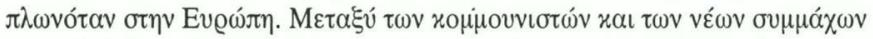

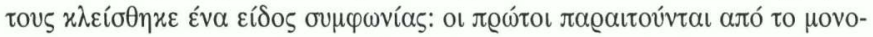

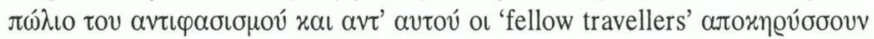

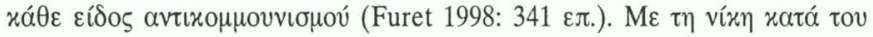

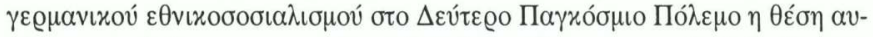

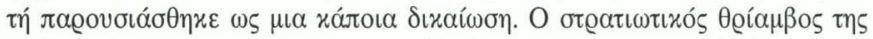

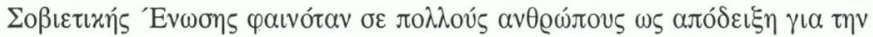

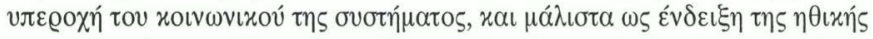

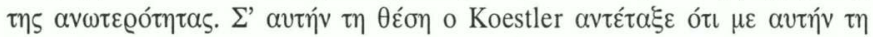

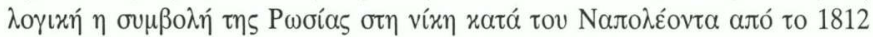

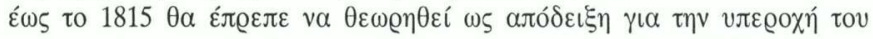

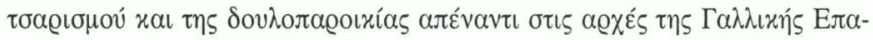

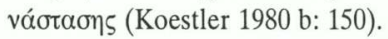

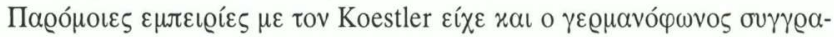

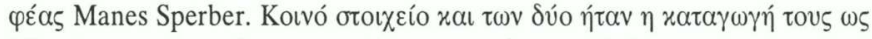

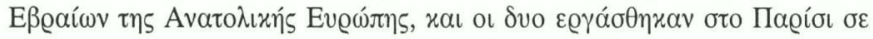

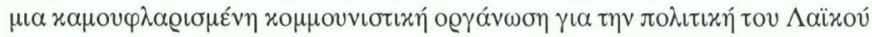

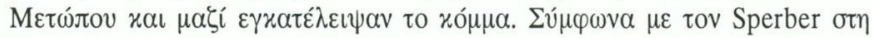

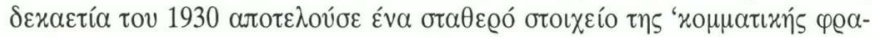

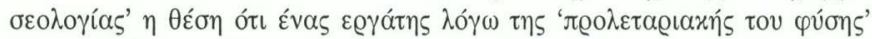

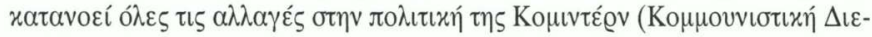

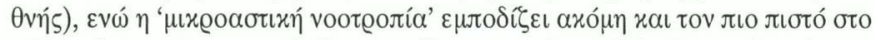

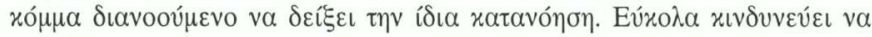

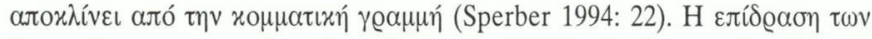

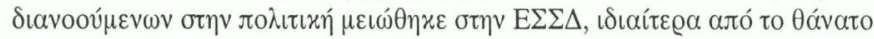

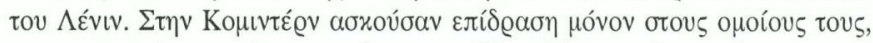

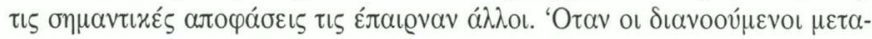

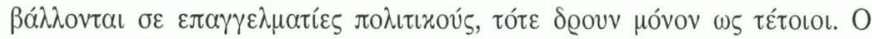

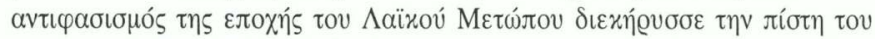

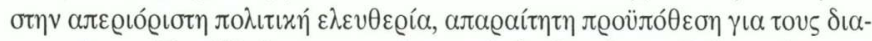

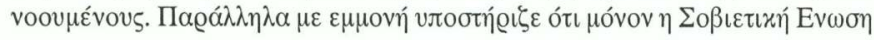




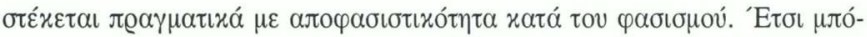

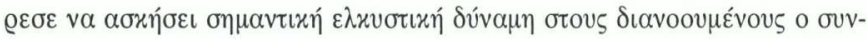

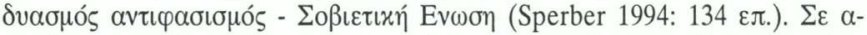

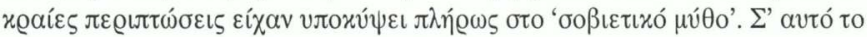

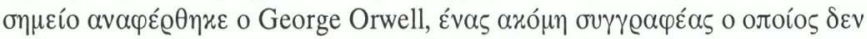

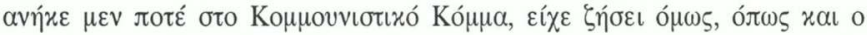

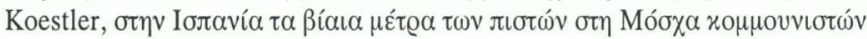

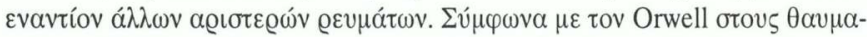

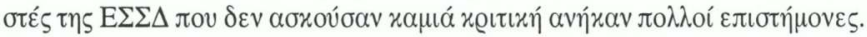

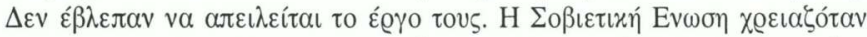

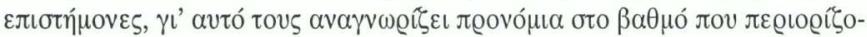

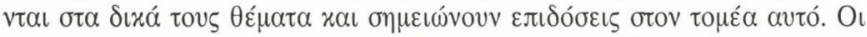

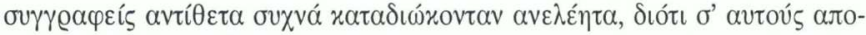

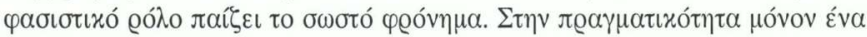

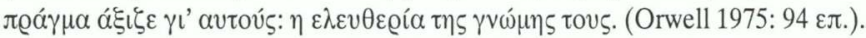

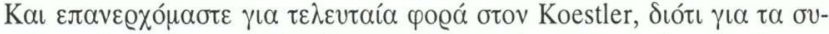

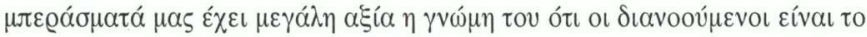

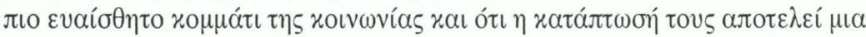

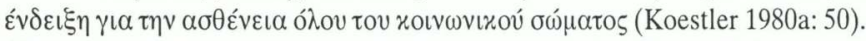

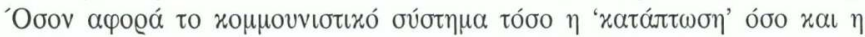

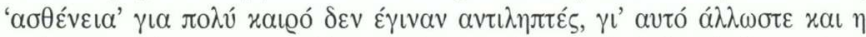

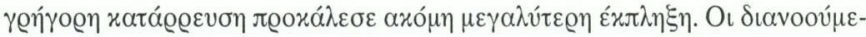

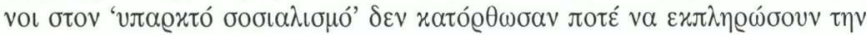

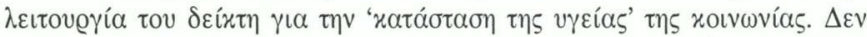

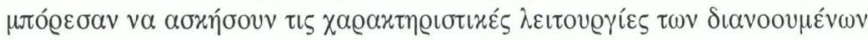

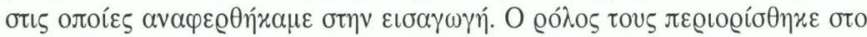

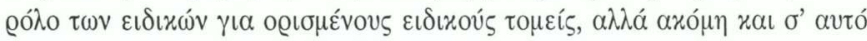

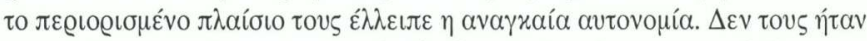

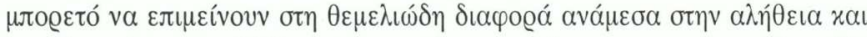

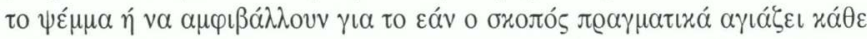

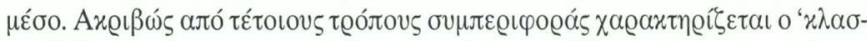

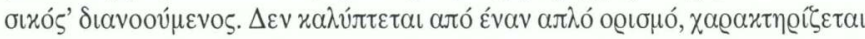

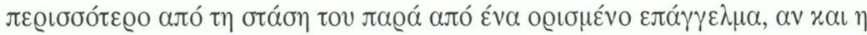

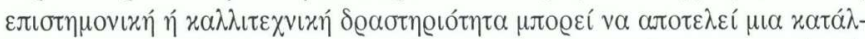

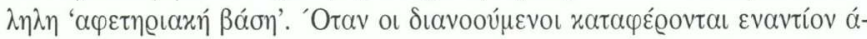

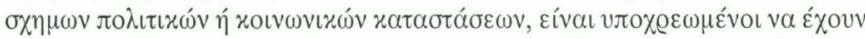

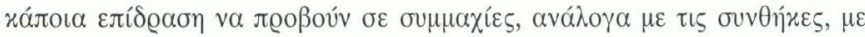




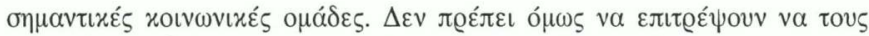

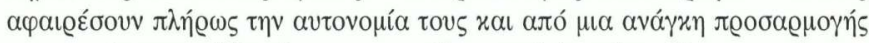

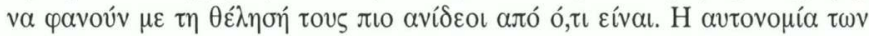

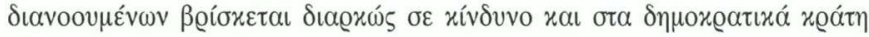

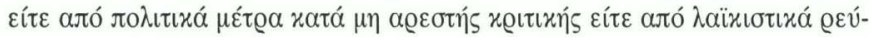

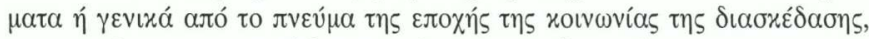

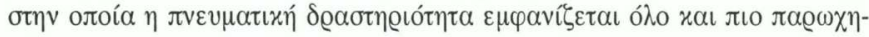

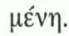

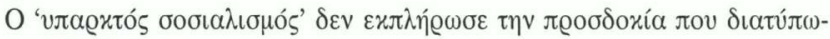

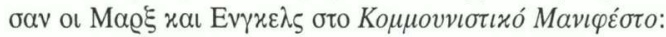

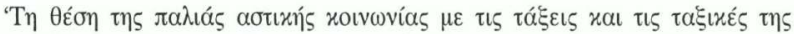

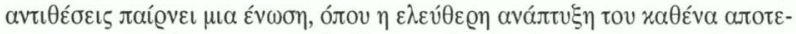

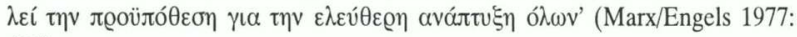
482).

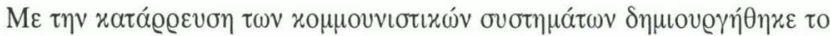

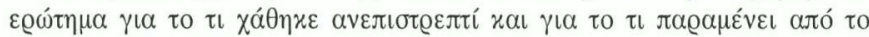

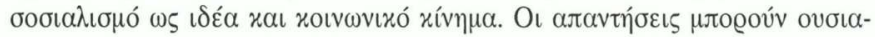

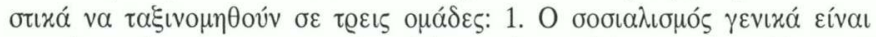

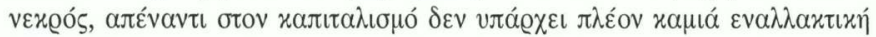

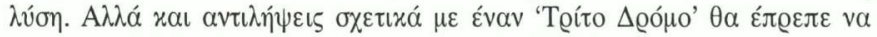

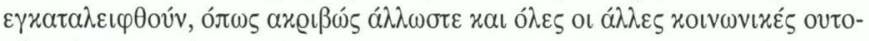

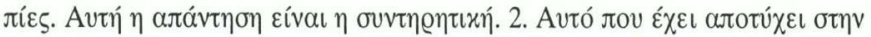

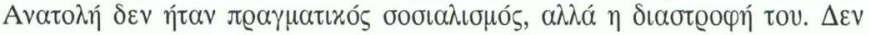

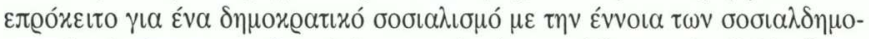

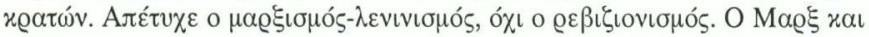

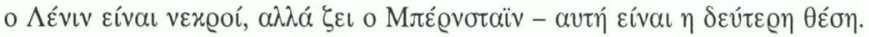

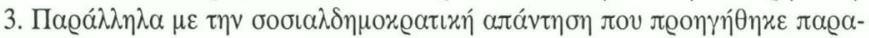

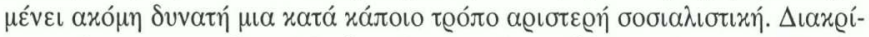

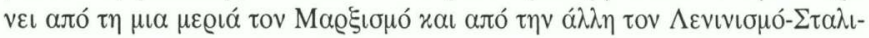

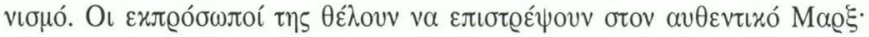

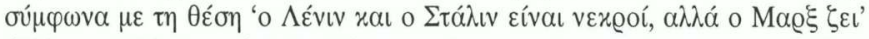

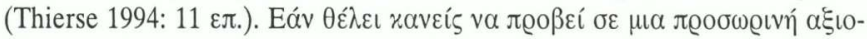

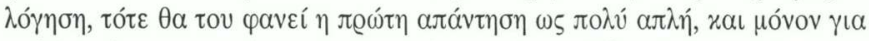

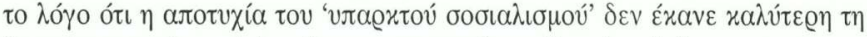

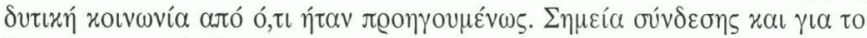

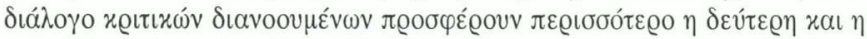

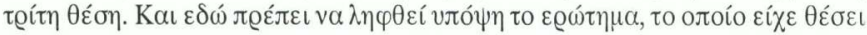


o pı

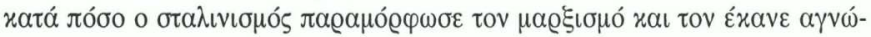

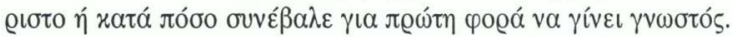

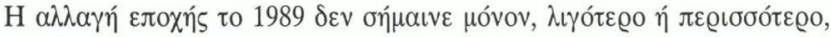

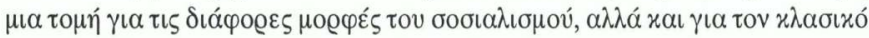

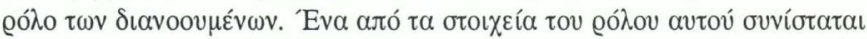

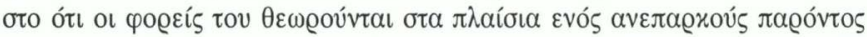

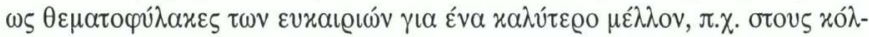

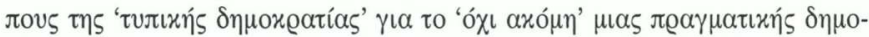

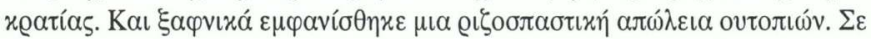

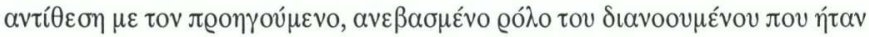

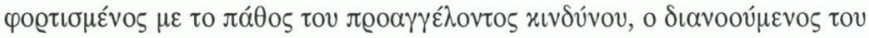

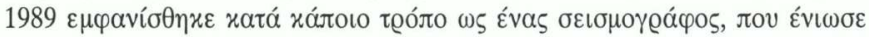

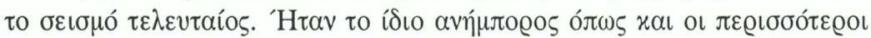

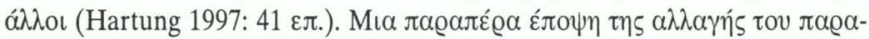

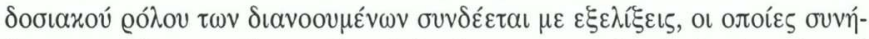

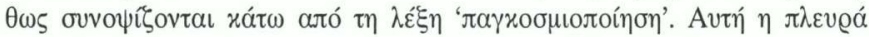

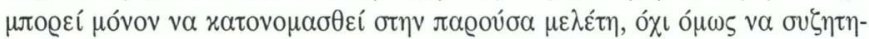

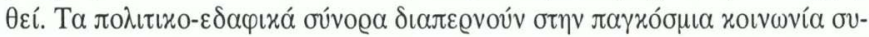

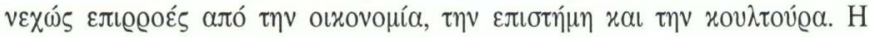

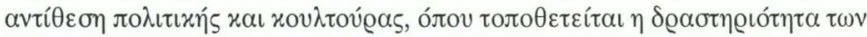

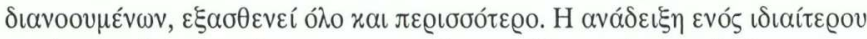

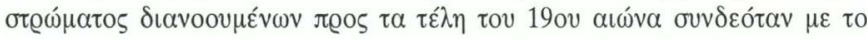

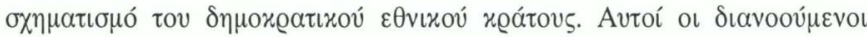

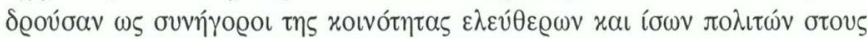

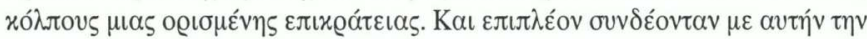

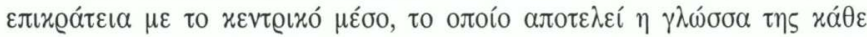

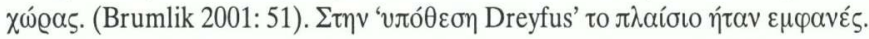

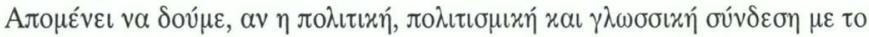

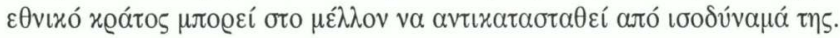

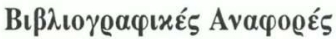

Ash, T. G. (1992). Ein Jahrhundert Wird Abgewählt. Aus den Zentren Mitteleuropas 1980 - 1990. München: Deutscher Taschenbuch Verlag (We The People. The Revolution of 89. Cambridge: Granta Books 1990). 
Bahro, R. (1977). Die Alternative. Zur Kritik des real existierenden Sozialismus. Köln - Frankfurt/M.: Europäische Verlagsanstalt.

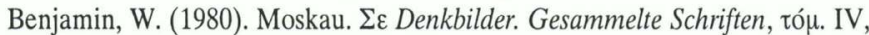
1. Frankfurt/M.: Suhrkamp.

Bering, D. (1982). Die Intellektuellen. Geschichte eines Schimpfworts. Frankfurt/ M. usw.: Ullstein.

Bourdieu, P. (1991). Die Intellektuellen und die Macht. Hamburg: VSA.

Brumlik, M. (2001). Intellektuelle, Postintellektuelle, Transintellektuelle. Thesen zum Probehandeln in der Weltgesellschaft. Neue Zürcher Zeitung, 29./30. 9., Nr. 226.

Feuchtwanger, L. (1993). Moskau 1937. Ein Reisebericht für meine Freunde. Berlin: Aufbau (Amsterdam: Querido 1937).

Furet, Fr. (1998). Das Ende der Illusion. Der Kommunismus im 20. Jahrhundert. München - Zürich: Piper (Le passé d'une illusion. Paris: Laffont 1995).

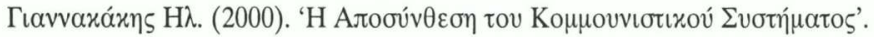

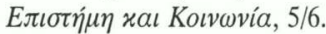

Groys, B. (1988). Gesamtkunstwerk Stalin. Die gespaltene Kultur in der Sowjetunion. München - Wien: Hanser.

Groys, B. (1995). Die Ethik der Avantgarde. $\sum \varepsilon$ : Die Erfindung Russlands. München - Wien: Hanser.

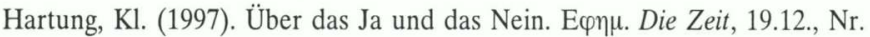
52.

Herling, G. (2000). Tagebuch bei Nacht Geschrieben. München - Wien: Hanser (polnisches Original Warschau 1998).

Hertfelder, Th. (2000). Kritik und Mandat. Zur Einführung. $\Sigma \varepsilon$ G. Hubinger/ T. Hertfelder (Hrsg.). Kritik und Mandat. Intellektuelle in der deutschen Politik. Stuttgart: Deutsche Verlagsanstalt.

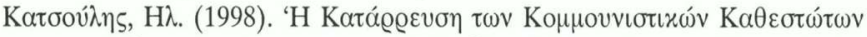

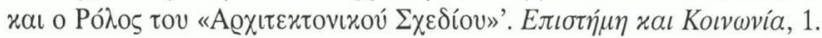

Koenen, G. (2000). Utopie der Säuberung. Was war der Kommunismus? Frankfurt/M.: Fischer Taschenbuch Verlag.

Koestler, A. (1979). Sonnenfinsternis. Roman. Frankfurt/M. usw.: Ullstein (Darkness at Noon. London 1940).

Koestler, A. $(1980 \alpha)$. Die Intelligenz als Gesellschaftsschicht. $\sum \varepsilon$ Der Yogi und der Kommissar. Auseinandersetzungen. Frankfurt/M.: Suhrkamp (The Yogi and the Commissar. London 1945). 
Koestler, A. (1980 b). Sowjet-Mythos und Wirklichkeit. $\Sigma \varepsilon$ Der Yogi und der Kommissar, ó.л.

Koestler, A. (1991). Das Rote Jahrzehnt. Wien - Zurich: Europa-Verlag

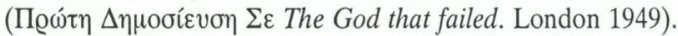

Kuhn, H. (1990). Bruch mit dem Kommunismus. Über autobiographische Schriften von Ex-Kommunisten im geteilten Deutschland. Münster: Westfälisches Dampfboot 1990.

Konrad, G./ Szelenyi, I. (1981). Die Intelligenz auf dem Weg zur Klassenmacht.

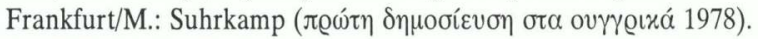

Lenin, W.I. (1976). Ein Schritt Vorwärts, Zwei Schritte Zurück (Die Krise in

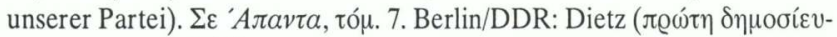

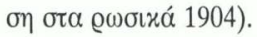

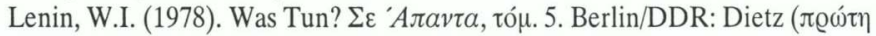

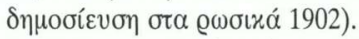

Marx, K./Engels, Fr. (1977). Manifest der Kommunistischen Partei. $\Sigma \varepsilon$ 'A $A \alpha$ -

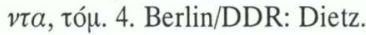

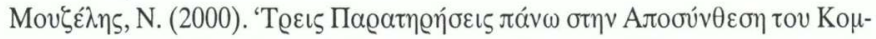

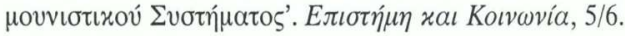

Orwell, G. (1975). Zur Verhinderung von Literatur. $\Sigma \varepsilon$ Rache ist Sauer. Erzählungen und Essays. Zürich: Diogenes (The Prevention of Literature. $\Sigma \varepsilon$ The Collected Essays. London 1968).

Russell, B. (1987). Die Praxis und Theorie des Bolschewismus. Darmstadt: Darmstädter Blätter 1987. (The Practice and Theory of Bolshevism. London 1920).

Rybakow, A. (1994). Stadt der Angst. Roman. München: Deutscher Taschenbuch Verlag (

Sperber, M. (1994). Bis man mir Scherben auf die Augen legt. All das Vergan-

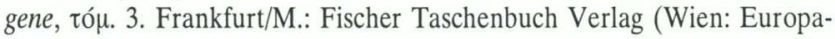
verlag 1977).

Thierse, W. (1994). Was bleibt vom Sozialismus? $\Sigma \varepsilon$ K. Benz-Overhage u.a., $\varepsilon \pi \iota \mu .$, Zwischen Rätesozialismus und Reformprojekt. Köln: SPW - Verlag. 